\title{
Convective Hot Air Drying of Chilli Pepper: Process Optimization and Modelling the Drying Kinetics and Quality Attributes of Dried Product
}

\section{Felix Ajuebor}

Federal Institute of Industrial Research, Oshodi, Lagos

Oluwafunmilayo Aworanti

Biochemical and Bioenvironmental Laboratory, Department of Chemical Engineering, Ladoke Akintola University of Technology, Ogbomoso

\section{Oluseye Agbede}

Separation Process/Unit Operation Laboratory, Department of Chemical Engineering, Ladoke Akintola University of Technology, Ogbomoso

\section{Samuel Agarry ( $\nabla$ seagarry@lautech.edu.ng )}

Biochemical and Bioenvironmental Laboratory, Department of Chemical Engineering, Ladoke Akintola University of Technology, Ogbomoso, Ladoke Akintola University of Technology Faculty of Engineering and Technology https://orcid.org/0000-0003-2080-0104

\section{Tinuade Afolabi}

Separation Process/Unit Operation Laboratory, Department of Chemical Engineering, Ladoke Akintola University of Technology, Ogbomoso

\section{Oladipupo Ogunleye}

Process System Engineering Laboratory, Department of Chemical Engineering, Ladoke Akintola University of Technology, Ogbomoso

\section{Research}

Keywords: Chilli pepper drying, Drying kinetics, Optimization, Product quality attributes, Quadratic regression models, Response surface

Posted Date: April 28th, 2020

DOI: https://doi.org/10.21203/rs.3.rs-23883/v1

License: (c) (1) This work is licensed under a Creative Commons Attribution 4.0 International License. Read Full License 


\title{
Convective Hot Air Drying of Chilli Pepper: Process Optimization and Modelling the Drying Kinetics and Quality Attributes of Dried Product
}

\author{
Felix Ajuebor', Oluwafunmilayo Aworanti2, Oluseye Omotoso Agbede ${ }^{3}$, Samuel \\ Enahoro Agarry ${ }^{2,3^{*}}$, Tinuade Jolaade Afolabi ${ }^{3}$, and Oladipupo Olaosebikan Ogunleye ${ }^{4}$ \\ ${ }^{1}$ Federal Institute of Industrial Research, Oshodi, Lagos, Nigeria \\ ${ }^{2}$ Biochemical and Bioenvironmental Laboratory, Department of Chemical Engineering, \\ Ladoke Akintola University of Technology, Ogbomoso, Nigeria. \\ ${ }^{3}$ Separation Process/Unit Operation Laboratory, Department of Chemical Engineering, \\ Ladoke Akintola University of Technology, Ogbomoso, Nigeria. \\ ${ }^{4}$ Process System Engineering Laboratory, Department of Chemical Engineering, Ladoke \\ Akintola University of Technology, Ogbomoso, Nigeria. \\ *Correspondence: seagarry@lautech.edu.ng
}

\begin{abstract}
:
The objectives of this study were to evaluate the individual and interactive effects of air velocity, relative humidity, drying temperature, and drying time on the cabinet hot air drying and quality attributes of chilli pepper as well as to determine the optimum process conditions using the rotatable central composite design (RCCD) of response surface methodology (RSM). The drying kinetics was also modelled. Four factors with three levels of RCCD were utilized: air velocity $(0.5-1.5 \mathrm{~m} / \mathrm{s})$, relative velocity $(65-75 \%)$, drying temperature $\left(50-70{ }^{\circ} \mathrm{C}\right)$, and drying time (180-360 min). Product moisture content (PMC), total plate count (TPC), protein content (PC), and carbohydrate content (CC) were evaluated as the quality attributes (responses). The results showed that the drying experimental data significantly $(p \leq 0.001)$ and adequately fitted into second-order quadratic regression models with $R^{2}(>0.95)$ to describe and predict all the responses. Drying time and drying temperature are the most significant drying conditions that exerted more pronounced linear and interactive effects on the dried chilli pepper quality attributes. The predicted optimum process conditions for the production of dried chilli pepper with minimum PMC and TPC as well as maximum PC and CC were obtained to be: drying temperature, $69.98^{\circ} \mathrm{C}$, air velocity, $1.46 \mathrm{~m} / \mathrm{s}$, relative humidity, $66.57 \%$, and drying time, 359.86 min. Four empirical models (Page, Newton, Logarithmic, and Henderson and Pabis) were fitted to the drying data and the Page model with $R^{2}(>0.95)$ best fitted the data to describe the drying kinetics.
\end{abstract}

Keywords: Chilli pepper drying; Drying kinetics; Optimization; Product quality attributes; Quadratic regression models; Response surface. 


\section{Introduction}

In convective hot-air drying system, the combined microscopic and macroscopic mechanisms of moisture transfer that occurs during drying is often described by drying kinetics (Salehi and Kashaninejad, 2018). The kinetics of drying is often times affected by the followings: (i) drying conditions which include drying air temperature, air relative humidity, air velocity, sample size and thickness (Sturm et al., 2012), (ii) types of dryer (Salehi and Kashaninejad, 2018), and (iii) type of materials to be dried (Salehi and Kashaninejad, 2018). Drying is a complex, unsteady, nonlinear, and dynamic process that leads to different levels of quality change depending on factors such as fresh-wet material properties, dimensions, shapes, chemical composition, and process conditions and thus needs proper monitoring (Md Saleh et al., 2019). If drying is inadequate, it gives rise to microbial infection, while over drying or unfavorable drying process set-up result in drastic quality loss. The associated quality changes with dried products include physical, nutritional properties, sensory properties, textural properties, structural properties, and rehydration properties as well as microbiological properties (Omolola et al., 2017; Guiné, 2018).

Modeling and optimization are important steps required in any thermal process for increasing process efficiency (Taheri-Garavand et al., 2017). Thus, mathematical and empirical models are commonly utilized for the prediction of material drying kinetics and for optimizing the operating parameters and conditions (Salehi and Kashaninejad, 2018). Drying time and moisture (mass) transfer during drying have been predicted using several proposed mathematical and empirical drying models (Agarry, 2017; Salehi and Kashaninejad, 2018; Turan and Firatligil, 2019; Senadeera et al., 2020). The drying model is very essential for process optimization, improvement of product quality and equipment design. It is of paramount importance to select optimal drying process conditions that would ensure the preservation of 
physical, chemical, sensory, and nutritional qualities of dried products without compromising energy minimization and footprint of carbon on the surroundings (Abano et al., 2014). The determination of these optimal drying conditions can be achieved through the use of (i) classical optimization technique that involves varying one-factor-at-a-time (OFAT) while holding the other factors constant and (ii) statistical optimization referred to as response surface methodology (RSM) (Myers et al., 2016). The drawbacks of classical optimization (OFAT method) are that, it is time consuming, cumbersome and does not provide information on the interactive effects of the operating factors or variables (Bas and Boyaci, 2007). The shortcomings of this OFAT method are overcome by RSM.

The RSM consists of a group of mathematical and statistical methods that can be utilized to define the relationships between the response and the independent variables (Bas and Boyaci, 2007; Myers et al., 2016). It employs statistical design of experiment (DOE) which seeks to minimize or reduce the number of experiments required. It provide information on the single or individual effects, interaction effects and curvilinear/quadratic effects of study variables as well as generates a mathematical model that can be represented graphically. The RSM has been successfully applied in various drying operations such as in osmotic dehydration (Agarry and Owabor, 2012), vacuum drying (Šumić et al., 2016), spray drying (Shishir et al., 2016), microwave drying (Omolola et al., 2015) and hot air drying operations of food products (Abano et al., 2014; Zhao et al., 2017; Ganje et al., 2018).

Chilli pepper belongs to the Capsicum frutescens family and is one of the widely used varieties of pepper. Chilli pepper is a fruit that is highly nutritive and contains macronutrients and micronutrients such as vitamins, minerals, carbohydrate, fats, dietary fiber, and proteins (Olatunji and Afolayan, 2018). It can be used as spices and flavour in dried and ground form (Isiduro et al., 1995; Giuffrida et al., 2013) and as a seasoning and thickener for making soups 
and stew (Kordylas, 1991). Due to its been seasonal, short shelf life of about 2 to 3 days (Mihindukulasuriya and Jayasuriya, 2015), highly perishable, and high post-harvest loss or wastage, several researchers have in recent times investigated the hot air drying of chilli pepper using cabinet or tray dryer (Tunde-Akintunde and Ajala, 2010; Muhidin and Hensel, 2012; Saengrayap et al., 2016; Montoya-Ballesteros et al., 2017), vacuum heat pump dryer (Artnaseaw et al., 2010), rotary dryer (Mihindukulasuriya and Jayasuriya, 2015), and fluidized bed dryer (Mihindukulasuriya and Jayasuriya, 2013) at different drying temperature. In all of these studies, the research workers only investigated the effects of pretreatment, drying method and temperature on the retention of color, ascorbic acid, reducing sugar, and capsaicin contents of dried chilli pepper which have resulted in a variation of findings due to different varieties of chilli pepper with different characteristics responding differently to the drying process. When drying takes place at temperatures that seems not to be high enough, microorganisms' survival can be very significant and thus should be considered as an important quality parameter for study.

Few studies as ascertained from literature have been done to investigate and evaluate the effects of pretreatment, drying methods, and temperature on the microbial load (or survival of microorganisms) of dried fruits and vegetables such as green onions, tomato, carrots, apple and cabbage (Garcia et al., 2010; Sohail et al., 2011; Martinazzo et al., 2016; Bourdoux et al., 2016; Dauda et al., 2019; Ochida et al., 2019). However, the effects or impacts of drying process conditions such as air velocity and relative humidity on the chilli drying process as well as on the quality attributes like nutritional properties (i.e. protein and carbohydrate content) and microbiological properties like microbial load (total plate count) of the dried chilli pepper have not been evaluated. In addition, there is paucity of information on the interactive 
effect of these drying process conditions on the hot air drying process of chilli pepper and its post-quality attributes as well as the optimization of these conditions using RSM.

Minimizing quality changes of fruits and vegetables after drying is paramount for quality assurance and final evaluation of the finished dried product. The inadequacy of drying information related to the product quality of specific varieties of chilli pepper generates qualityrelated problems for the consumer and food market. Hence, due to these available research gaps, there is the need to evolve specific drying strategies that simultaneously minimize the quality degradation of red chilli pepper, while maximizing the production efficiency under optimum operating process conditions. The main purposes of this present study are therefore to (i) evaluate the independent and combined or interactive effects of drying temperature, air velocity, relative humidity, and drying time on the drying and quality attributes of dried chilli pepper, (ii) optimize the drying process conditions that would improve or maximize the dryproduct quality in relation to minimum moisture content and minimum total plate count (microbial load) as well as maximum protein and carbohydrate contents using RSM, and (iii) model the kinetics of drying using known empirical drying models in the literature.

\section{Materials and methods}

\section{Materials and equipment}

The cabinet-tray dryer $(65 \mathrm{~cm}$ x $55 \mathrm{~cm}$ x $90 \mathrm{~cm})$ used for this experiment was self-designed and fabricated (Fig. 1). It was designed and fabricated using aluminum sheets lined with layer of $2.5 \mathrm{~cm}$ thick armaflex used as insulator and wrapped with $0.5 \mathrm{~mm}$ thick heat resistant aluminum foil to control heat loss by conduction. The drying chamber had slots for each drying tray which are perforated for effective airflow within the chamber. The dryer is made up of three sections, the energy source (electricity), blower and the drying cabinet sections. The energy source is located behind the dryer while the blower is located in the middle of the drying 
chamber and has a power rating of $0.5 \mathrm{hp}$. The blower helps in circulating heat for effective and efficient heat flow rate within the drying chamber. Humidification of the air entering into the drying chamber was done using a water aerosol (i.e. $1 \mathrm{~L}$ water trigger sprayer (Sprayon Model SO-075)) (Sigge et al., 1998) manually operated behind the air-blower until the desired relative air humidity is attained which was measured using a hygrometer (PCE- 555 Model). The velocity of the air in metres per seconds $(\mathrm{m} / \mathrm{s})$ delivered by the air-blower was measured with the use of a hot-wire anemometer (PCE-009 Model) linked to the air-blower. The inside and outside temperature of the dryer was checked using a mercury thermometer.

The fresh chilli pepper samples were purchased from local market at Idi-Oro $\left(6.5219^{\circ}\right.$ N, 3.3565 E), Lagos State of South-West Nigeria. The samples were sorted, washed with tap water, cleaned with tissue paper and weighed. The samples were kept for some hours to achieve equilibrium temperature with the environment before usage as to obtain a better result. This is because the sample temperature could be higher than the temperature of the environment.

\section{Preliminary drying procedure}

The fresh chilli pepper samples with an average moisture content of $84.98 \%$ were not subjected to any form of pre-treatment. The chilli pepper samples were sliced into a thickness of $2 \mathrm{~mm}$ and $1 \mathrm{~kg}$ of the samples were weighed and loaded into the cabinet-tray dryer. The chilli pepper drying was carried out (using one factor-at a-time (OFAT) procedure) at a temperature of 40 ${ }^{\circ} \mathrm{C}$, an air velocity of $1.5 \mathrm{~m} / \mathrm{s}$ and a relative humidity of $60 \%$, respectively. At intervals of 30 min, the samples were withdrawn to measure the weight until a constant weight was achieved. This procedure was repeated for temperature $\left(50-70{ }^{\circ} \mathrm{C}\right)$, air velocity $(0.3-2.0 \mathrm{~m} / \mathrm{s})$, and relative humidity $(65-80 \%)$, respectively. The whole experimental tests carried out were done in triplicate $(\mathrm{n}=3)$ and the mean values were utilized. 


\section{Design of drying experiment using rotatable central composite design (RCCD)}

RSM of Design-Expert 6.0.8 (State Ease, USA) software which involved four factors with three levels rotatable central composite design (RCCD) was used. The values of the independent drying process variables used for the RCCD are: air velocity $\left(X_{1}\right), 0.5-1.5 \mathrm{~m} / \mathrm{s}$, relative humidity $\left(X_{2}\right), 65-75 \%$, drying temperature $\left(X_{3}\right), 50-70{ }^{\circ} \mathrm{C}$, and drying time $\left(X_{4}\right), 180-360$ min. These values utilized were obtained from the preliminary drying experiments. The RCCD generated 30 experimental runs. The response variables are product moisture content (PMC) ( $\left.Y_{P M C}\right)$, protein content $(\mathrm{PC})\left(Y_{P C}\right)$, carbohydrate content $(\mathrm{CC})\left(Y_{C C}\right)$, and total plate count (TPC) $\left(Y_{T P C}\right)$, respectively. The RCCD experimental design for the okra drying process is presented in Table 1. Each of the experimental run was done in triplicate $(n=3)$ of which the mean value of the response variable was utilized.

\section{Product quality analysis}

The properties of the dried product analyzed as indices for quality are PMC, PC, CC, and TPC. The PMC of plantain samples was gravimetrically determined by the method of oven drying in which the samples were dried to constant weight at $105^{\circ} \mathrm{C}$ (AOAC, 2015). Kjedahl nitrogen standard method (AOAC, 2015) and the phenol-sulphuric acid method (Dubois et al., 1956) was utilized for the determination of PC and CC, respectively. The TPC was performed using standard pour plate method (Harrigan and McCance, 1976). The initial values of PMC, PC, $\mathrm{CC}$, and TPC in the fresh chilli pepper are 5.66 (kg moisture/kg dry matter or $84.98 \%$ wet basis), $3.09 \%, 5.56 \%$, and $5.70 \times 10^{2} \mathrm{cfu} / \mathrm{g}$, respectively.

\section{Statistical analysis}

The chilli pepper drying experimental data was analyzed using the Design-Expert 6.08 software ((state-Ease, Inc., Minneapolis MN, USA)). A quadratic polynomial model as given in Eq. (1) 
was used for the prediction of the response variables based on multiple linear regression analysis.

$$
Y=\beta_{o}+\sum \beta_{i} X_{i}+\sum \beta_{i i} X_{i}^{2}+\sum \beta_{i j} X_{i j}
$$

where $Y=$ predicted response, $\beta_{o}=$ offset term (i.e. the constant that fixed the response at the experiment centre point), $\beta_{i}=$ linear coefficient, $\beta_{i i}=$ quadratic coefficient, and $\beta_{i j}=$ interaction coefficient. $X_{i}(i=1,2,3)$ and $X_{j}(j=1,2,3)(i \neq j)$ are the drying process independent variables. The quadratic polynomial model adequacy to fit the okra drying experimental data was assessed and evaluated using the variance analysis (ANOVA) and regression analysis with the following components: lack of fit, coefficient of variation $(\mathrm{CV})$, coefficient of determination $\left(R^{2}\right)$, Adjusted $R^{2}$, Predicted $R^{2}$, and Adequate Precision. The model terms were evaluated for each response by the probability value (i.e. p-value).

\section{Optimization of drying process conditions and dried product quality attributes}

In optimizing the drying process conditions for chilli pepper, the desirability function in numerical optimization tool of RSM in Design-Expert statistical software was applied. In carrying out the optimization process, the target criteria or objective was set as maximum value for the response variable (protein content) and minimum values for the response variables (moisture content and total plate count), while the values of the four independent variables were set at the ranges being studied. The predicted experimental drying process variables/conditions with the highest desirability were selected and recorded. The predicted and observed experimental results of the responses obtained at optimum drying process conditions were recorded. 


\section{Verification of predicted optimum process conditions}

For verification of the predicted optimum drying process conditions as obtained using the numerical optimization tool, laboratory chilli pepper drying experiments were conducted under the predicted optimum drying process conditions obtained. The experimental observed values of the response variables (protein content, carbohydrate content, moisture content and total plate count) were recorded and then compared with the predicted values in order to check the validity of the models. The percentage error $(\% \mathrm{E})$ between the experimental value and the predicted value is calculated as provided in Eq. (2) (Agarry and Ogunleye, 2012):

$$
\% E=\frac{Z_{j}-Z_{i}}{Z_{j}} \times 100
$$

Where $Z_{i}$ is the predicted value and $Z_{j}$ is the experimental value.

\section{Empirical modelling of the kinetics of chilli peper drying}

The empirical drying models that were fitted to the chilli pepper kinetics data include the Page model (Eq. (3)), Newton model (Eq. (4)), Logarithmic model (Eq. (5)), and Handerson and Pabis model (Eq. (6)) (Afolabi and Agarry, 2014; Agarry, 2017):

Page model:

$$
M R=\exp \left(-k t^{n}\right)
$$

Newton model:

$$
M R=\exp (-k t)^{n}
$$

Logarithmic model:

$$
M R=a^{*}(-k t)+c
$$

Henderson and Pabis model: $M R=a *(-k t)$

Where

$$
M R=\frac{M_{t}}{M_{o}}
$$

and $a, c, n$, are empirical constants; $k$, drying constant; $t$, drying time; $M R$, moisture ratio. The model that best fit the data was selected according to statistical criteria. The best of fit was determined using two parameters: highest values for coefficient of determination $\left(R^{2}\right)$ and smallest values for root mean square error (RMSE) using equations (8) - (9), respectively. 


$$
\begin{aligned}
& R^{2}=1-\left[\frac{\sum_{i}^{N}\left(M R_{p r e, i}-M R_{\text {exp }, i}\right)^{2}}{\sum_{i=1}^{N}\left(\overline{M R_{p r e, i}}-M R_{\text {exp }, i}\right)^{2}}\right] \\
& R M S E=\left[\frac{1}{N} \sum_{i=1}^{N}\left(M R_{\exp _{i}}-M R_{p r e_{i}}\right)^{2}\right]^{\frac{1}{2}}
\end{aligned}
$$

Where $M R_{\text {exp } i}$ the experimental moisture ratio value, $M R_{\text {prei }}$ is the predicted moisture ratio value and, $N$ is the number of observations. These modules (Eqs. (8) and (9)) have been used to evaluate the goodness of fit of different mathematical models (Agarry, 2017; Turan and Firatligil, 2019).

\section{Results and discussion}

\section{Statistical modelling and analysis of variance (ANOVA)}

The drying experimental data was fitted to the quadratic regression model (Eq. (1)) and the coefficients of the model were obtained using the Design Expert (6.08) software. The coefficients of the model equation for all the process variables and all the responses are provided in Table 3.

In order to test the fit of the model, variance analysis (ANOVA) where the Fischer test (Fvalue), probability value (p-value) and coefficient of determination $\left(R^{2}\right)$ (measures the degree of fit goodness) were determined and evaluated (Table 4). The $R^{2}$ and the Adjusted (Adj) $R^{2}$ values are high (> 0.95) for all the models representing the responses (Table 3). The relatively high values of $R^{2}$ obtained shows a high degree of correlation between the observed experimental value and predicted values. The respective "Pred $R^{2}$ values are high $(>0.90)$ and are in reasonable agreement with their corresponding $\operatorname{Adj} R^{2}$ and thus the models are adequate. "Adequate Precision" measures the signal to noise ratio and a ratio greater than 4 is desirable and adequate. The respective Adequate (Adeq) Precisions for all the response models are high 
(>35) which indicates that the noise to signal ratio for all the respective models are adequate. The ANOVA for all the response quadratic regression models revealed that the models are highly significant, as evident from the very low probability value $(<0.0001)$ of the F -test. In addition, values of Prob > F less than 0.05 indicate that the model terms are significant and values greater than 0.1000 indicate that the terms of the model are insignificant.

\section{Evaluation of the effect of drying process conditions on product quality attributes}

After the carrying out of 30 experimental runs of the RCCD, the results of the statistical experiment are presented in Table 2.

\section{Product moisture content and total plate count}

PMC is the most important property that is intimately associated with the entire quality and long shelf life of the food product (Shishir et al., 2016). Appropriate moisture or water content in food materials is very necessary to avoid microbial growth (i.e. microbial load) and product deterioration and degradation (Silva et al., 2017). Hence, low moisture contents are recommended (Silva et al., 2017). The TPC sometimes referred to as standard plate count is a widely used technique for evaluation of microorganisms in foods as it provides information concerning the total microbial load in foods (Brackett, 1993). Thus TPC (microbial) analysis was done on the dried products to determine whether the products are free from microorganisms or pathogens and hence, safe for consumption. Table 2 show the results for the PMC and TPC of the dried chilli pepper product after the drying process. From Table 2, it is observed that run numbers 1 and 2, 3 and 4, 5 and 6, 7 and 8,9 and 10,11 and 12,13 and 14, and 15 and 16 were carried out at the same drying conditions of relative humidity, temperature, and drying time but at varying air velocities and the results shows that both the PMC and TPC decreases as the air velocity (A) gradually increased from low level of $0.5 \mathrm{~m} / \mathrm{s}$ (coded value -1$)$ to high level of $1.5 \mathrm{~m} / \mathrm{s}$ (coded value +1$)$ as better represented by a diagnostic perturbation plot 
presented in Fig. 2(a) and 2(b) for PC and TPC, respectively. This observation indicates that increase in air velocity results in increased moisture removal from the fresh sample and thus a decrease in the amount of moisture (PMC) retained in the dried product. The reduction in the moisture content led to the observed drastic reduction in the microbial load (TPC). Over the range of coded value -1 to coded value +1 of air velocity, the PMC and TPC did not changed over a wide range as observed in Fig. 2(a) and 2(b).

Run numbers 1 and 3,2 and 4, 5 and 7, 6 and 8, 9 and 11, 10 and 12,13 and 15,14 and 16, and 19 and 20 were performed at the same drying conditions of air velocity, temperature and drying time but at different relative humidity and the results revealed that the PMC and TPC increases as the relative humidity (B) gradually increased from low level of $65 \%$ (coded value -1$)$ to high level of $75 \%($ coded value +1$)$ as better represented by a diagnostic perturbation plot presented in Fig. 2(a) and 2(b) for PC and TPC, respectively. This observation showed that increase in relative humidity leads to decrease in moisture removal from the fresh samples and hence an increase in the amount of moisture retained in the dried product (i.e. higher PMC). The increase in the PMC led to the observed rise in the microbial load (TPC). This observation of increased PMC due to increase in relative humidity has similarly been reported for the tray drying of green bell pepper (Sigge et al., 1998), celery leaves (Román and Hensel, 2001), and apple (Zlatanovic et al., 2013), respectively.

Effect of drying temperature was investigated at the same condition of air velocity, relative humidity and drying time (run numbers 1 and 5, 2 and 6, 3 and 7, 4 and 8, 9 and 13,10 and 14, 11 and 15, 12 and 16, and 21 and 22) and the results demonstrated that increase in drying temperature (C) from low level of $50{ }^{\circ} \mathrm{C}$ (coded value -1) to high level of $70{ }^{\circ} \mathrm{C}$ (coded value +1$)$ as better represented by a diagnostic perturbation plot presented in Fig. 2(a) and 2(b) for PC and TPC, respectively led to respective decrease in the PMC and TPC. It is observed from Fig. 2(a) and (b) that over the range of coded value -1 to coded value +1 of drying 
temperature, the PMC and TPC respectively changed over a wide range. This observation revealed that increase in the drying temperature resulted to increase in the amount of moisture removed from the fresh samples and thus a decrease in the amount of moisture or water retained in the dried product (i.e. lower PMC). The reduced PMC resulted in the observed decrease in the TPC. A decrease in moisture content due to increase in drying temperature has been observed and reported by Zlatanovic et al. (2013) for convective tray drying of apple, Shishir et al. (2016) for the spray drying of pink quava, and Taheri-Garavand and Meda (2018) for the hot air drying of savory leaves. Similarly, a decrease in microbial load as a result of increase in drying temperature has also been observed and reported for the drying of green onions (Garcia et al., 2010; Martinazzo et al., 2016) and tomato (Dauda et al., 2019; Ochida et al., 2019).

Furthermore, run numbers 1 and 9, 2 and 10, 3 and 11, 4 and 12, 5 and 13, 6 and 14, 7 and 15, 8 and 16, 23 and 24, and 23 and 25 were carried out at the same drying conditions of air velocity, relative humidity and drying temperature, however, at different drying time (D) and the results illustrates that both the PMC and TPC decreased as the drying time increased from low level of $180 \mathrm{~min}$ (coded value -1$)$ to high level of $360 \mathrm{~min}($ coded value +1$)$ as better represented by a diagnostic perturbation plot presented in Fig. 2(a) and 2(b) for PC and TPC. Fig. 2(a) and 2(b) also revealed that over the range of coded value -1 (180 $\mathrm{min}$ ) to +1 (360 $\mathrm{min})$ of drying temperature, the PMC and TPC respectively changed over a wide range. This observation also demonstrated that moisture removal from the fresh chilli pepper samples increased with increase in the drying time and thus lower moisture content in the dried product (i.e. lower PMC) with reduced or lower TPC. This observed reduction in PMC in relation to increase in drying time is in accord with other workers observation for the drying of fruits and vegetables (Idah et al., 2010; Zhao et al., 2017; Senadeera et al., 2020). 
Overall, from the results in Table 2, at temperature range of $50-70{ }^{\circ} \mathrm{C}$; air velocity range of $0.5-1.5 \mathrm{~m} / \mathrm{s}$; relative humidity range of $65-75 \%$; and drying time range of $180-360$ min; the TPC (microbial load or total viable bacterial count) correspondingly ranged from $0.468 \times 10^{2}-0.306 \times 10^{2} \mathrm{cfu} / \mathrm{g} ; 0.473 \times 10^{2}-0.306 \times 10^{2} \mathrm{cfu} / \mathrm{g} ; 0.465 \times 10^{2}-0.306 \times 10^{2} \mathrm{cfu} / \mathrm{g} ;$ and $0.468 \times 10^{2}-0.306 \times 10^{2} \mathrm{cfu} / \mathrm{g}$. These corresponding values are lower than the value of $5.70 \times 10^{5}$ cfu/g obtained for the fresh chilli pepper. The differences observed between the values for the dried product and the fresh product may be attributed to the synergistic effects of thermal inactivation and dehydration inactivation based on temperature intensity, drying environment characteristic (such as relative humidity, pressure, air velocity etc) and drying time (Bourdoux et al., 2016; Dauda et al., 2019). The high moisture content which invariably means high water activity of the fresh chilli pepper might be responsible for the high TPC or microbial load. This is because microorganisms thrive more in such favorable moisture environment. The TPC values of the dried product are within the accepted range of $<10^{5} \mathrm{cfu} / \mathrm{g}$ specified by WHO (1998) and International Commission on Microbiological Specification for Foods (ICMSF) (Van Schothorst, 1998). Thus the dried chilli pepper are within the limit acceptable for consumption.

It can be observed from Table 4 that air velocity, relative humidity, drying temperature, and drying time had significant effect $(p \leq 0.05)$ on both the PMC and TPC. Furthermore, it is observed that among all the drying process conditions, drying time exerted more pronounced linear effect (i.e. maximum effect) as indicated by higher regression coefficient value. That is, both the PMC and TPC are mostly and negatively influenced by drying time followed by the drying temperature, air velocity and positively influenced by relative humidity, respectively. The quadratic regression equations for both the PMC and TPC relating to coded levels of drying process parameters were respectively obtained as Eq. (10) and Eq. (11): 


$$
\begin{aligned}
& Y_{P M C}=2.99-0.24 X_{1}+0.18 X_{2}-0.44 X_{3}-0.78 X_{4}+0.12 X_{1}^{2}-0.11 X_{2}^{2}-0.068 X_{3}^{2}+0.060 X_{4}^{2} \\
& -0.094 X_{1} X_{2}-0.081 X_{1} X_{3}-0.13 X_{1} X_{4}-0.0044 X_{2} X_{3}+0.12 X_{2} X_{4}-0.28 X_{3} X_{4} \\
& Y_{T P C}=42.10-1.14 X_{1}+0.92 X_{2}-2.56 X_{3}-4.01 X_{4}+0.53 X_{1}^{2}-0.68 X_{2}^{2}-0.57 X_{3}^{2}-0.27 X_{4}^{2} \\
& -0.35 X_{1} X_{2}-0.51 X_{1} X_{3}-0.49 X_{1} X_{4}+0.15 X_{2} X_{3}+0.50 X_{2} X_{4}-1.04 X_{3} X_{4}
\end{aligned}
$$

The $R^{2}$ values obtained for PMC and TPC response models are 0.9867 and 0.9905 , respectively, indicating a good degree of model fit. It is to be noted that a coefficient with positive sign is indicative of a synergistic impact or effect, while coefficient with a negative sign depicts an antagonistic influence or impact (Taheri-Garavand et al., 2017). The interaction effects of the drying process variables on both the PMC and TPC are illustrated in the three dimensional (3D) response surface plots (Figs. 1 and 2).

Figures 3(a) and 4(a) show the interaction effect of relative humidity and air velocity on PMC and TPC, respectively. Both the PMC and TPC are significantly and negatively influenced by the interaction of relative humidity and air velocity. Since the objective function is to minimize PMC and TPC, Figs. 3(a) and 4(a) displayed that at a fixed drying temperature and drying time, decrease in relative humidity with simultaneous increase in the air velocity resulted in a decrease in the PMC and TPC, respectively. This observation indicates that high air velocity and low relative humidity brings about low PMC and TPC in the dried chilli pepper product.

The impact of the interaction of air velocity and drying temperature on both the PMC and TPC is significantly negative and this is depicted in Figs. 3(b) and 4(b), respectively. The response surface plots indicates that at a fixed relative humidity and drying time, the PMC and TPC of the dried chilli pepper decreased respectively with increase in both the air velocity and drying temperature. These 3D response plots explains that both the air velocity and drying temperature has individual negative influence on both the PMC and TPC of chilli pepper as the individual coefficient of both air velocity and drying temperature is negative. However, the 
impact of drying temperature is more than that of air velocity as the individual coefficient value is higher for drying temperature (PMC, -0.44; TPC, -2.56) than for air velocity (PMC, -0.24; TPC, -1.14). Thus Figs. 3(b) and 4(b) suggest that at a fixed relative humidity and drying time, the air velocity and drying temperature has to be increased for a dried chilli pepper with lower PMC and TPC to be obtained.

Figures 3(c) and 4(c) illustrates the influence of the interaction of air velocity and drying time on PMC and TPC, respectively. There is a negative mutual impact of air velocity and drying time on the PMC and TPC, respectively (Table 3). The 3D plots in Figs. 3(c) and 4(c) demonstrates that at a fixed relative humidity and drying temperature, PMC and TPC of the dried chilli pepper declined as the air velocity and drying time simultaneously increased. That is, dried chilli pepper with a lower PMC and TPC will be obtained at a higher air velocity and a higher drying time. Drying time exerted more negative influence on the PMC than the air velocity as the individual coefficient was higher (PMC, -0.78; TPC, -4.01) than that of air velocity (PMC, -0.24; TPC, -1.14).

The interaction effect between relative humidity and drying time on PMC and TPC is provided in Figs. 3(d) and 4(d), respectively. The 3D response surface plots indicates that at a fixed air velocity and drying temperature, the PMC and TPC of the dried chilli pepper decreases with decrease in relative humidity and increase in drying time. These 3D response plots demonstrates that the relative humidity has a positive influence and the drying time has a negative influence on the respective PMC and TPC of dried chilli pepper as the individual coefficient of the relative humidity and the drying time is respectively positive and negative and their interaction effect is positive. However, the impact of drying time is more than that of the relative humidity as the individual coefficient value is higher for the drying time (PMC, 0.78; TPC, -4.01) than for the relative humidity (PMC, 0.18; TPC, 0.92). Thus Figs. 3(d) and 4(d) suggest that at a fixed air velocity and drying temperature, the relative humidity has to be 
decreased while the drying time has to be increased for dried chilli pepper with lower PMC and TPC to be obtained.

Figures 3(e) and 4(e) respectively provides the 3D response surface plots of the effect of interaction between drying temperature and drying time on the PMC and TPC of dried chilli pepper. There is a significant $(p \leq 0.05)$ negative mutual impact of drying temperature and drying time on the PMC and TPC, respectively (Table 3). The plots in Figs. 3(e) and 4(e) show that the drying of chilli pepper at a fixed air velocity and relative humidity, the PMC and TPC respectively decreased with simultaneous increase in the drying temperature and drying time. That is, a dried chilli pepper with lower PMC and TPC will be obtained at both higher temperature and higher drying time. A similar observation of a decrease in moisture content with increase in both the drying time and drying temperature has been reported for the drying of tomato by Idah et al. (2010), mango seed kernel by Ekorong et al. (2015) as well as for squid-laver snack by Zhao et al. (2017). Drying time exerted more negative influence on the PMC than the drying temperature as the individual linear coefficient was higher (PMC, -0.78 ; TPC, -4.01) than that of drying temperature (PMC, -0.44; TPC, -2.56).

\section{Protein and carbohydrate contents}

Proteins are extremely important constituents of living cells in that they act as structural molecules, represent storage forms of carbon and nitrogen as well as regulate metabolism (Famurewa and Olumofin, 2015). Table 2 provides the results for the PC of the dried chilli pepper product after drying. It can be observed that run numbers 1 and 2, 3 and 4, 5 and 6, 7 and 8, 9 and 10, 11 and 12, 13 and 14, and 15 and 16 were performed at the same drying conditions of relative humidity, temperature, and drying time but at varying air velocities (A) and the results depicts that the PC and CC increases as the air velocity gradually increased from low level of $0.5 \mathrm{~m} / \mathrm{s}$ (coded value -1$)$ to high level of $1.5 \mathrm{~m} / \mathrm{s}$ (coded value +1$)$ as better 
represented by a diagnostic perturbation plot presented in Fig. 2(c) and 2(d) for PC and TPC, respectively. This increase may probably be as a result of increased moisture/water removal leading to solute/solid concentration of the PC and CC in the dried product (BabanovskaMilenkovska et al., 2016). Fig. 2(c) and 2(d) also show that over the range of coded value -1 $(0.5 \mathrm{~m} / \mathrm{s})$ to coded value $+1(1.5 \mathrm{~m} / \mathrm{s})$ of air velocity, the $\mathrm{PC}$ and $\mathrm{CC}$ respectively did not changed over a wide range.

Run numbers 1 and 3,2 and 4, 5 and 7, 6 and 8, 9 and 11, 10 and 12,13 and 15,14 and 16, and 19 and 20 were performed at the same drying conditions of air velocity, temperature and drying time but at different relative humidity (B) and the results as provided in Table 2 revealed that the $\mathrm{PC}$ and $\mathrm{CC}$ respectively decreased in relation to steady increase in the relative humidity from low level of $65 \%$ (coded value -1 ) to high level of $75 \%$ (coded value +1 ) as better represented by a diagnostic perturbation plot presented in Fig. 2(c) and 2(d) for PC and $\mathrm{CC}$, respectively. This observation may be due to the fact that there is a decrease in moisture removal from the fresh samples as a result of increased relative humidity and hence decrease in the degree or level of PC and CC solutes concentration.

Effect of drying temperature (C) was investigated at the same condition of air velocity, relative humidity and drying time (run numbers 1 and 5, 2 and 6, 3 and 7, 4 and 8, 9 and 13,10 and 14, 11 and 15, 12 and 16, and 21 and 22) and the results as given in Table 2 demonstrates that an increased drying temperature from low level of $50^{\circ} \mathrm{C}$ (coded value -1 ) to high level of $70{ }^{\circ} \mathrm{C}$ (coded value +1 ) as better represented by a diagnostic perturbation plot presented in Fig. 2(c) and 2(d) for PC and TPC resulted in an increased PC and CC of the dried product, respectively. Also, it can be observed from Fig. 2(c) and 2(d) that over the range of $-1\left(50{ }^{\circ} \mathrm{C}\right)$ to $+1\left(70{ }^{\circ} \mathrm{C}\right)$ of drying temperature, there is a respective change of $\mathrm{PC}$ and $\mathrm{CC}$ over a wide range. This observation explains the fact that increased drying temperature resulted in an increased moisture removal from the fresh samples and thus leading to an increased 
concentrated PC and CC that are retained in the dried product (Babanovska-Milenkovska et al., 2016). The PC and $\mathrm{CC}$ values (dry basis) obtained at these varying temperatures $\left(40-80{ }^{\circ} \mathrm{C}\right)$ are greater than the values for the fresh chilli pepper (Table 2). Similar observation has respectively been reported for the drying of tomato $\left(30-90{ }^{\circ} \mathrm{C}\right)$ by Idah et al. $(2010)$, for the drying of Moringa leave $\left(30-60^{\circ} \mathrm{C}\right)$ by Ayegba et al. (2017), and for the drying of cabbage $\left(80{ }^{\circ} \mathrm{C}\right.$ ) by Duarte et al. (2019). The reason(s) for this observation may probably be due to the type of drying method used (i.e. convective hot air drying method) (Duarte et al., 2019) and variety of the chilli pepper (Babanovska-Milenkovska et al., 2016). Morris et al. (2004) have reported in the literature that heating generally improves food digestibility thereby making some nutrients more available as in the case of legume proteins which after heating become more digestible due to anti-nutrient (like trypsin inhibitors) inactivation. According to Branden and Tooze (1998), melting or denaturation temperature varies for different proteins, however, proteins are generally denatured at high temperature. Idah et al. (2010) and Ayegba et al. (2017) have respectively reported an increase in protein content with respect to increase in drying temperature for the drying of tomato and Moringa leave. Pendre et al. (2012) also observed an initial increase in protein content in the drying of okra as temperature increased from 50 to 60 ${ }^{\circ} \mathrm{C}$ and above $60{ }^{\circ} \mathrm{C}$ it gradually decreased, while Famurewa and Olumofin (2015) as well as Isik et al. (2019) have reported a decline in protein content as well as an increase in carbohydrate content with steady rise in drying temperature for okra and bee pollen drying, respectively.

Furthermore, run numbers 1 and 9, 2 and 10, 3 and 11, 4 and 12, 5 and 13, 6 and 14, 7 and 15, 8 and 16, 23 and 24, and 23 and 25 were conducted at the same conditions of air velocity, relative humidity and drying temperature, however, at different drying time (D) and the results indicates that the PC and CC increased with increase in drying time from low level of $180 \mathrm{~min}$ (coded value -1$)$ to high level of $360 \mathrm{~min}$ (coded value +1$)$ as better represented by 
a diagnostic perturbation plot presented in Fig. 2(c) and 2(d) for PC and TPC, respectively. Fig. 2(c) and 2(d) also illustrates that over the range of coded value -1 (180 $\mathrm{min})$ to coded value +1 (360 min) of drying time, the respective PC and CC changed over a wide range. This observation is as a result of increased moisture removal from the fresh samples due to increase in the drying time and thereby causing the PC to be more concentrated.

Generally as observed from the results in Table 2, at air velocity range of $0.5-1.5 \mathrm{~m} / \mathrm{s}$, relative humidity range of $65-75 \%$, temperature range of $50-70{ }^{\circ} \mathrm{C}$, and drying time range of 180-360 min, the PC and CC values of the dried chilli pepper respectively ranged from 9.66$12.84 \%$ and $33.33-37.14 \%$; $9.66-12.84 \%$ and $33.33-37.14 \%$; and $9.66-12.84 \%$ and $33.33-$ $37.14 \%$. The values obtained at these varying range of drying conditions are relatively higher than the PC and CC values of the fresh chilli pepper which are $3.09 \%$ and $5.56 \%$, respectively. This observation indicates that the range of the different drying conditions employed in this work generally preserved the $\mathrm{PC}$ and $\mathrm{CC}$ in the dried chilli peppper.

It is seen from Table 4 that air velocity, relative humidity, drying temperature, and drying time had significant effect $(p \leq 0.05)$ on PC and CC, respectively. It is also observed that among all the drying process conditions, drying time exerted more pronounced positive linear effect (i.e. maximum effect) as indicated by higher regression coefficient value and then followed by drying temperature and air velocity. The PC and $\mathrm{CC}$ were significantly and negatively influenced by relative humidity. The quadratic regression equations for PC and CC relating to coded levels of drying process parameters (air velocity, relative humidity, drying temperature, and drying time) are obtained as Eq. (12) and Eq. (13), respectively:

$$
\begin{aligned}
& Y_{P C}=10.62+0.22 X_{1}-0.15 X_{2}+0.48 X_{3}+0.78 X_{4}-0.11 X_{1}^{2}+0.086 X_{2}^{2}+0.072 X_{3}^{2}+0.057 X_{4}^{2} \\
& +0.088 X_{1} X_{2}+0.12 X_{1} X_{3}+0.10 X_{1} X_{4}-0.039 X_{2} X_{3}-0.11 X_{2} X_{4}+0.29 X_{3} X_{4} \\
& Y_{C C}=34.68+0.29 X_{1}-0.15 X_{2}+0.56 X_{3}+1.01 X_{4}-0.17 X_{1}^{2}+0.22 X_{2}^{2}+0.059 X_{3}^{2}-0.056 X_{4}^{2} \\
& +0.078 X_{1} X_{2}+0.13 X_{1} X_{3}+0.12 X_{1} X_{4}+0.0025 X_{2} X_{3}-0.14 X_{2} X_{4}+0.26 X_{3} X_{4}
\end{aligned}
$$


The $R^{2}$ values obtained for these PC and CC response models are 0.9886 and 0.9930 respectively, which indicates a good model fit.

The interaction effects of the drying process variables on PC and CC are respectively illustrated in the three dimensional (3D) response surface plot presented in Figs. 5 and 6. Figs. 5(a) and 6(a) shows the interaction effect between relative humidity and air velocity on PC and $\mathrm{CC}$, respectively. The PC and CC are significantly $(p \leq 0.05)$ and positively influenced by the interaction of relative humidity and air velocity. Since the target is to respectively maximize PC and CC, Figs. 5(a) and 6(a) demonstrates that at a fixed drying temperature and drying time, decrease in relative humidity with simultaneous increase in the air velocity resulted in an increase in both the PC and CC. This shows that high air velocity and low relative humidity produces a dried product that is high in $\mathrm{PC}$ and $\mathrm{CC}$, respectively.

The influence of the interaction between air velocity and drying temperature on the respective PC and CC is significantly $(p \leq 0.05)$ positive and this is depicted in Figs. 5(a) and 6(b), respectively. The 3D plots indicates that at a fixed relative humidity and drying time, the PC and CC of the dried chilli pepper respectively increased with increase in both the air velocity and drying temperature. The response plots shows that both the air velocity and drying temperature has individual significant positive influence on both the PC and CC of dried chilli pepper. However, the influence of drying temperature is more than that of air velocity as the individual coefficient value is higher for drying temperature $(\mathrm{PC}, 0.44 ; \mathrm{CC}, 0.56)$ than for air velocity (PC, 0.22; CC, 0.29). Therefore, Figs. 5(b) and 6(b) suggest that at a fixed relative humidity and drying time, the air velocity and drying temperature has to be increased for a dried chilli pepper with higher PC and CC to be produced.

Figures 5(c) and 6(c) both illustrates the effect of the interaction of air velocity and drying time on PC and CC, respectively. There is a positive mutual impact of air velocity and 
drying time on both the PC and CC (Table 3). The 3D response plots in Figs. 5(c) and 6(c) displays that at a fixed relative humidity and drying temperature, both the PC and $\mathrm{CC}$ of the dried product increased as both the air velocity and drying time mutually increased. That is, dried product with both high $\mathrm{PC}$ and $\mathrm{CC}$ will be obtained at a high air velocity and high drying time. Drying time exerted more positive effect on both the $\mathrm{PC}$ and $\mathrm{CC}$ than the air velocity as the individual regression coefficient is higher $(\mathrm{PC}, 0.78 ; \mathrm{CC}, 1.01)$ than that of air velocity $(\mathrm{PC}$, 0.22; CC, 0.29).

The effect of interaction between relative humidity and drying time on both the $\mathrm{PC}$ and CC is illustrated in Figs. 5(d) and 6(d), respectively. The 3D surface plot reveals that at a fixed air velocity and drying temperature, both the $\mathrm{PC}$ and $\mathrm{CC}$ of the dried chilli pepper increased in relation to decreased relative humidity and increased drying time. This plot displays that relative humidity has a negative impact and the drying time has a positive impact on both the $\mathrm{PC}$ and $\mathrm{CC}$ of dried chilli pepper and their interaction effect is negative. However, the effect of drying time is more than that of the relative humidity as the individual coefficient value is higher for the drying time $(\mathrm{PC}, 0.78: \mathrm{CC}, 1.01)$ than for the relative humidity $(\mathrm{PC},-0.15 ; \mathrm{CC}$, -0.15). Thus Figs. 5(d) and 6(d) suggest that at a fixed air velocity and drying temperature, the relative humidity has to be decreased while the drying time has to be increased for dried chilli pepper with high PC and CC to be obtained.

The response surface plots that illustrates the effect of interaction between drying temperature and drying time on both the $\mathrm{PC}$ and $\mathrm{CC}$ of dried chilli pepper are presented in Figs. 5(e) and 6(e), respectively. There is a significant $(p \leq 0.05)$ positive mutual impact of drying temperature and drying time on both the PC and CC (Table 3). The plots in Figs. 5(e) and 6(e) respectively show that the drying of chilli pepper at a fixed air velocity and relative humidity, there is an increase in both the $\mathrm{PC}$ and $\mathrm{CC}$ of the dried chilli pepper as the drying temperature and drying time mutually increased. That is, a dried chilli pepper with high PC and CC will be 
obtained at both high temperature and high drying time. Drying time exerted more positive effect on both the PC and CC than the drying temperature as the individual linear coefficient is higher $(\mathrm{PC}, 0.78 ; \mathrm{CC}, 1.01)$ than that of drying temperature $(\mathrm{PC}, 0.48 ; \mathrm{CC}, 0.56)$.

\section{Optimum drying process conditions for chilli pepper and verification}

Predicted optimum drying conditions for the production of dried chilli pepper were determined using the numerical optimization tool of Design Expert (6.08) statistical software based on desirability function. According to this tool, the target goal for air velocity, relative humidity, drying temperature, and drying time was each set in the ranges that is been investigated while the responses (PMC and TPC) was each set on minimize and PC and CC was each set on maximize. The experimental drying process conditions with the highest desirability was selected and then verified. The predicted optimum (uncoded) values obtained for air velocity, relative humidity, drying temperature, and drying time are: $1.46 \mathrm{~m} / \mathrm{s}, 66.57 \%, 69.98{ }^{\circ} \mathrm{C}$, and $359.96 \mathrm{~min}$, respectively, to achieve a dried chilli pepper with minimum PMC of $0.90 \mathrm{~kg}$ moisture/kg dry mass, minimum TPC of $30.51 \mathrm{cfu} / \mathrm{g}$, maximum PC of $12.87 \%$ and maximum CC of $37.22 \%$, respectively. The desirability function was 1.000 (Fig. 7).

Verification experiment was carried out at these predicted optimum drying process conditions to verify the minimum PMC, minimum TPC, maximum PC, and maximum CC, respectively. From the verification experiment, the minimum PMC, minimum TPC, maximum PC and maximum CC obtained for the dried chilli pepper were $0.87 \mathrm{~kg}$ moisture/ $\mathrm{kg}$ dry weight, $29.90 \mathrm{cfu} / \mathrm{g}, 12.90 \%$ and $37 \%$, respectively. The percent errors between predicted and validated experimental or actual values calculated according to Eq. (2) were found to be $-3.45 \%,-2.04 \%$, $0.23 \%$ and $-0.59 \%$ which explicitly indicated that there are no significant differences between them. 


\section{Modelling the thin layer drying kinetics}

The preliminary experimental results of moisture content variation with drying time at different air velocity, relative humidity and drying temperature were fitted to the four different drying model (Newton, Page, Logarithm, and Handerson and Pabis) equations given in Eq. (3) - Eq. (6). The parameters of the different model equations were determined with the use of the nonlinear regression (NLR) tool of MATLAB 6.5 version computer software. The model that had the highest coefficient of determination $\left(R^{2}\right)$ and the lowest root mean square error (RMSE) was selected (Senadeera et al., 2020). The values of $R^{2}$ and RMSE obtained by the NLR analysis are presented in Table 5. The results in Table 5 show that at different air velocity, relative humidity and drying temperature, the value of $R^{2}$ was greater than 0.90 , indicating a good fit (Shahzad et al., 2013; Afolabi and Agarry, 2014). However, the $R^{2}$ value for the Page model at the different air velocity, relative humidity and drying temperature was comparatively the highest and with the lowest RMSE value. Thus, the Page model may be proposed to be the best model to describe the drying kinetics or behavior of chilli pepper. Similar observation has been reported for the HAD of red pepper (Agarry, 2017), tomato (Doymaz, 2007), red chillies (Tunde-Akintunde and Ajala, 2010), quinces (Tzempelikos et al., 2014), basil leaves (TaheriGaravandi et al., 2015), bitter leaf (Agarry, 2017), thyme leaves (Turan and Firatligil, 2019), and persimmon slices (Senadeera et al., 2020), respectively. The result revealed that under cabinet hot air drying of chilli pepper best described by Page model, the drying constant ' $k$ ' increases with increase in air velocity as well as with increase in drying temperature, while the empirical constant ' $n$ ' generally decreases with increase in both air velocity and drying temperature. However, the drying constant ' $k$ ' decreases with increasing relative humidity while the empirical constant ' $n$ ' increases with increasing relative humidity. Arora et al. (2006) 
and Agarry (2017) have also reported similar observation of an increase in drying constant with increase in temperature in the drying of red chillies, red pepper and bitter leaf, respectively.

\section{Conclusion}

Response surface methodology was effectively used to describe the effects of drying conditions in the retention of carbohydrate and protein (nutritional properties) and also, the decline of moisture content (physical property) and total plate count (microbial quality). The most significant drying conditions that exerted more pronounced linear (individual) and interactive effects on the quality attributes (moisture content, protein content, carbohydrate content and total plate count) of dried chilli pepper in the course of convective hot air drying are drying time and drying temperature while the least significant are air velocity as well as relative humidity. Second-order quadratic regression models can adequately predicts the quality attributes of dried chilli pepper with respect to drying process conditions of air velocity, relative humidity, temperature and drying time in the course of convective hot air drying. The kinetics of chilli pepper drying can most suitably be described by Page empirical drying model. The drying treatments generally retained the protein and carbohydrate contents (nutritional properties) of fresh chilli pepper as well as reduced the microbial load to the acceptable limit

allowed for consumption. However, further studies will be performed in our laboratory to evaluate the effects of physical and chemical pretreatments, temperature and drying time on the nutritional and microbial qualities of different varieties of chilli pepper using different types of drying equipment.

\section{Statement of novelty}

The novelty of this present work lies in the fact that the individual and interactive or combined effects of air velocity, relative humidity, temperature and drying time on the quality attributes 
(nutritional (protein and carbohydrate contents) and microbial qualities) of dried chilli pepper were evaluated. These drying process conditions that would result in optimum quality attributes of the dried chilli pepper were optimized using rotatable central composite design of the response surface methodology. This study is majorly different from existing few reported studies that have only focused on the investigation of the single effects of temperature, pretreatment and type of drying methods on ascorbic acid, color and capsuin of the dried chilli pepper.

\begin{abstract}
Abbreviations
ANOVA: analysis of variance; PC: protein content; PMC: product moisture content; RCCD: rotatable central composite design; RSM: response surface methodology; TPC: total plate count.
\end{abstract}

\title{
Acknowledgements
}

The authors wishes to thank the technical staff of the Department of Chemical Engineering, Ladoke Akintola University, Ogbomoso as well as the staff of the Production Department of Federal Institute of Industrial Research, Oshodi, Lagos for their support in performing this study.

\section{Authors' contributions}

All authors listed in this paper have contributed to the conduct and completion of the study. All authors read and approved the final manuscript.

\section{Funding}

This present study received no funding.

\section{Availability of data and materials}

All data generated or analyzed during this study are included in this article. 


\section{Ethics approval and consent to participate}

Not applicable.

\section{Consent for publication}

All authors approved the consent for publishing the manuscript in bioresources and bioprocessing.

\section{Competing interests}

The authors declare that they have no competing interests.

\section{Author details}

${ }^{1}$ Federal Institute of Industrial Research, Oshodi, Lagos, Nigeria; ${ }^{2}$ Biochemical and Bioenvironmental Laboratory, Department of Chemical Engineering, Ladoke Akintola University of Technology, Ogbomoso, Nigeria; ${ }^{3}$ Separation/Unit Operation Laboratory, Department of Chemical Engineering, Ladoke Akintola University of Technology, Ogbomoso, Nigeria; ${ }^{4}$ Process System Engineering Laboratory, Department of Chemical Engineering, Ladoke Akintola University of Technology, Ogbomoso, Nigeria.

\section{References}

Abano EE, Ma H, Qu W (2014) Optimization of drying conditions for quality dried tomato slices using response surface methodology. J Food Process Preservat 38: 996-1009.

Afolabi TJ, Agarry SE (2014) Thin layer drying kinetics and modelling of okra (Abelmoschus Esculentus (L.) Moench) slices under natural and forced convective air drying. Food Sci Qual Manage 28: 35 - 50 .

Agarry SE, Ogunleye OO. (2012) Box-behnken designs application to study enhanced bioremediation of soil artificially contaminated with spent engine oil using biostimulation strategy. Int J Energy Environ Eng 3: 31-44.

Agarry SE, Owabor CN (2012) Statistical optimization of process variables for osmotic dehydration of okra (Abelmoschus esculentus) in sucrose solution. Nig J Technol 31 (3): 370-382.

Agarry SE (2017) Modelling the drying characteristics and kinetics of hot air-drying of unblanched whole red pepper and blanched bitter leaf slices. Turkish J Agric- Food Sci Technol 5(1): $24-32$. 
Ananthan R, Subash K, Longvah T (2014) Assessment of nutrient composition and capsaicinoid content of some red chilies. Proceedings of International Conference on Food and Nutrition Technology, Singapore, 72: 1-4.

AOAC (Association of Official Analytical Chemists) (2015). Official Methods of Analysis. $16^{\text {th }}$ Ed. Washington DC, pp. 202

Arora S, Bharti S, Sehgal VK (2006) Convective drying kinetics of red chillies Drying Technol 24:189-193.

Artnaseaw A, Theerakulpisut S, Chatchai B (2010) Development of a vacuum heat pump dryer for drying chilli. Biosystem Eng 105: 130-138.

Ayegba C, Makinde O, Obigwa P, Orijajogun J (2017) Effect of drying temperature on nutritional content of moringa oleifera leave. World J Food Sci Technol 1 (3): 93-96.

Babanovska-Milenkovska F, Karakasova L, Petanovska-Ilievska B, Manasievska-Simic S, Miskoska-Milevska E, Velkoska-Markovska L, Jankulovska M (2016) Change in the quality properties of two different pepper varieties in fresh and dried condition. J Int Sci Publicat-Agric \& Food 4: 250-259.

Baş D, Boyacı İH (2007) Modeling and optimization I: usability of response surface methodology. J Food Eng 78(3): 836-845.

Bourdoux S, Li D, Rajkovic A, Devlieghere F, Uyttendaele M (2016) Performance of drying technologies to ensure microbial safety of dried fruits and vegetables. Comprehen Rev Food Sci Food Saf 15 (6): 1056-1066.

Branden C, Tooze J (1998) Introduction to Protein Structures, 2nd edition. London: Taylor and Francis.

Dauda A, Abiodun O, Salami T, Akintayo O (2019) Chemical and microbiological evaluation of dried tomato slices for Nigerian system. Glob J Nutri Food Sci. 1(5): 1-4.

Doymaz I (2007). Air-drying characteristics of Tomatoes. J Food Eng 78(4): 1291-1297.

Duarte C, Sousa P, Rocha S, Pinheiro R, Vaz Velho M (2019) The effect of different drying processes on physicochemical characteristics and antioxidant activity of brassica spp. cultivars from Northern Atlantic Portugal. Chem Eng Trans 75: 421-426.

Dubois M, Gilles KA, Hamilton JK, Rebers PA, Smith F (1956) Colorimetric method for determination of sugars and related substances. Analytical Chem 28: 350-356.

Ekorong FJAA, Zomegni G, Desobgo SCZ, Ndjouenkeu R (2015) Optimization of drying parameters for mango seed kernels using central composite design. Bioresour Bioproces 2: 8-16.

Famurewa JA, Olumofin KM (2015). Drying kinetics and influence on the chemical characteristics of dehydrated okra (Abelmoschus esculentus) using cabinet dryer. European J Eng Technol 3 (2): 7-19. 
Ganje M, Jafari SM, Farzaneh V, Malekjani N (2018) Kinetics modelling of color deterioration during thermal processing of tomato paste with the use of response surface methodology. Heat and Mass Transfer 54 (12): 3663-3671.

Garcia SV, Brumovsky LA, Fretes RM, Schmalko ME. 2010. Influence of drying temperature on the physical and microbiological parameters and the quality of dried green onion. Dry Technol 28(12):1435-44.

Giuffrida D, Dugo P, Torre G, Bignardi C, Cavazza A, Corradini C, Dugo G (2013) Characterization of 12 capsicum varieties by evaluation of their carotenoid profile and pungency determination. Food Chem 140: 794-802.

Guiné RPF (2018) The Drying of foods and its effect on the physical-chemical, sensorial and nutritional properties. Int J Food Eng 4 (2): 93 - 100.

Harrigan WF, McCance ME (1976) Laboratory Methods in Food and Dairy Microbiology. (2014 Ed.) London Academic Press, pp. 532.

Idah PA, Musa JJ, Olaleye ST (2010) Effect of temperature and drying time on some nutritional quality parameters of dried tomatoes. AU J Technol 14(1): 25-32

Isiduro E, Cotter DJ, Fernandez GCJ, Southward GM (1995) Colour retention in red chilli powder as related to delayed harvest. J Food Sci 60 (5): 1075-1077.

Isik A, Ozdemir M, Doymaz I (2019) Effect of hot air drying on quality characteristics and physicochemical properties of bee pollen. Food Sci Technol 39(1): 224-231

Kordylas JM (1991) Processing and preservation of Tropical and Subtropical Foods. Macmillan Education ltd. London, UK. pp.414

Martinazzo AP, Correa F, Luiz C, Teodoro, Carlos E deS, Berbert PA (2016) Drying kinetics and microbiological quality of green onions. Revista Ceres 63(6): 769-774.

Md Saleh R, Kulig B, Hensel O, Sturm B (2019) 1nvestigation of dynamic quality changes and optimization of drying parameters of carrots (Daucus carota var. laguna). J Food Process Eng e13314 https://doi.org/ 10.1111/jfpe.13314

Mihindukulasuriya SDF, Jayasuriya HPW (2015) Drying of chilli in a combined infrared and hot air rotary dryer. J Food Sci Technol 52(8): 4895-4904.

Mihindukulasuriya SDF, Jayasuriya HPW (2013) Mathematical modeling of drying characteristics of chilli in hot air oven and fluidized bed dryers. Agric Eng Int CIGR J 15: 154-166.

Montoya-Ballesteros LC, Gonz'alez-Le'on A, Mart'inez-N'ũ̃ez YJ, Robles-Burgue no MR, Garc'1a-Alvarado MA, Rodr' '1guez-Jimenes GC (2017) Impact of open sun drying and hot air drying on capsaicin, capsanthin, and ascorbic acid content in chiltepin (Capsicum annuum L. var. glabriusculum). Revista Mexicana de Ingeniería Química 16 (3): 813-825.

Morris A, Barnett A, Burrows O (2004) Effect of processing on nutrient content of foods. Cajarticles 37: 160-164.

Muhiden R, Hansen RC (2012) Influence of pretreatment on drying rates of chilli pepper. Agric Eng Int: CIGR J 14(1): 55-63.

Myers RH, Montgomery DC, Anderson-Cook CM (2016) Response surface methodology: process and product optimization using designed experiments: John Wiley \& Sons. 
Ochida CO, Itodo AU, Anhwange BA, Nwanganga PA, Abah CN (2019) Chemical and microbial quality evaluation of fresh tomato and its processed products using FTIR, SEM and GC-MS. J Postharvest Technology 7(3): 30-44.

Olatunji TL, Afolayan AJ (2018) The suitability of chili pepper (Capsicum annuum L.) for alleviating human micronutrient dietary deficiencies: A review. Food Sci. Nutri 6 (8): 22392251.

Omolola AO, Jideani AIO, Kapila PF, Jideani VA (2015) Optimization of microwave drying conditions of two banana varieties using response surface methodology. Food Sci Technol Campinas 35(3): 438-444.

Pendre NK, Nema PK, Sharma HP, Rathore SS, Kushwah SS (2012) Effect of drying temperature and slice size on quality of dried okra (Abelmoschus esculentus (L.) Moench). J Food Sci Technol 49(3):378-381.

Perasiriyan V, Kathikadevi B, Sivakumar T (2013) Optimization of drying process for vegetable and fish by solar tunnel dryer. Int J Food, Agric Vet Sci 3(2): 51-57.

Román, F, Hensel O (2001) Effect of air temperature and relative humidity on the thin-layer drying of celery leaves (Apium graveolens var. secalinum). Agric Eng Int: CIGR J 13(2): 111.

Saengrayap R, Boonlap N, Boonsorn U (2016) Effect of pre-treatment methods on the color changes during drying of red chilli (Capsicum frutescens L.). Proceedings of MATEC Web of Conferences 62, 02009. DOI: 10.1051/matecconf/20166202009

Salehi F, Kashaninejad M (2018) Modeling of moisture loss kinetics and color changes in the surface of lemon slice during the combined infrared-vacuum drying. Infor Proces Agric 5(4): $516-523$.

Salehi F, Kashaninejad M, Jafarianlari A (2017) Drying kinetics and characteristics of combined infrared-vacuum drying of button mushroom slices. Heat and Mass Transfer 53 (5): 1751-1759.

Senadeera W, Adiletta G, Önal, B, Di Matteo M, Russo P (2020) Influence of different hot air drying temperatures on drying kinetics, shrinkage, and colour of persimmon slices. Foods 9: $101-112$.

Shahzad F, Rufi T, Vishal K (2013) Performance evaluation and process optimization of potato drying using hot air oven. J Food Proces Technol 4:273-282.

Shishir MRI, Taip FS, Ab. Aziz, Talib RA, Sarker Md SH (2016) Optimization of spray drying parameters for pink guava powder using RSM. Food Sci Biotechnol 25(2): 461- 468.

Sigge GO, Hansmann CF, Joubert E (1998) Effect of temperature and relative humidity on the drying rates and drying times of green bell peppers (Capsicum annuиm L). Drying Technol 16(8): 1703-1714.

Silva BG, Fileti AMF, Foglio MA, Vieira Rosa P deT, Taranto OP (2017) Effects of different drying conditions on key quality parameters of pink peppercorns (Schinus terebinthifolius Raddi). J Food Qual 2017: 1-12. Article ID 3152797. https://doi.org/10.1155/2017/3152797

Sohail M, Ayub M, Ahmad I, Ali B, Dad F (2011) Physicochemical and microbiological evaluation of sun dried tomatoes in comparison with fresh tomatoes 44(3):106-9. 
Sturm B, Hofacker WC, Hensel O (2012) Optimizing the drying parameters for hot-air-dried apples. Drying Technol 30(14): 1570-1582.

Šumić, Z., Vakula A, Tepić A, Čakarević J, Vitas J, Pavlić B (2016) Modeling and optimization of red currants vacuum drying process by response surface methodology (RSM). Food Chem 203: 465-475.

Taheri-Garavand A and Meda V (2018). Drying kinetics and modeling of savory leaves under different drying conditions. International Food Research Journal, 25(4), 1357-1364.

Taheri-Garavand A, Karimi F, Karimi M, Lotfi V, Khoobbakht G (2017) Hybrid response surface methodology-artificial neural network optimization of drying process of banana slices in a forced convective dryer. Food Sci Technol Int 24(4): 277-291.

Taheri-Garavand A, Rafiee S, Keyhani A (2015) Effect of temperature, relative humidity and air velocity on drying kinetics and drying rate of basil leaves. Electronic J Environ Agric Food Chem 10(4): 2075-2080.

Tasirin SM, Kamarudin SK, Ghani JA, Lee KF (2007) Optimization of drying parameters of bird's eye chilli in a fluidized bed dryer. J Food Eng 80: 695-700.

Tunde-Akintunde TY, Ajala A (2010) Air drying characteristics of chilli pepper. Int J Food Eng 6(7): 67-98.

Turan OY, Firatligil E (2019) Modelling and characteristics of thin layer convective air-drying of thyme (Thymus vulgaris) leaves. Czech J Food Sci 37: 128-134.

Tzempelikos DA, Vouros AP, Bardakas AV, Filios AE, Margaris DP (2014) Case studies on the effect of the air drying conditions on the convective drying of quinces. Case Studies Thermal Eng. 3:79-85.

Van Schothorst M (1998) (International Commission on Microbiological Specification for Foods) Principles for the Establishment of Microbiological Food Safety Objectives and Related Control Measures. Food Control 9: 379-384

WHO - Word Health Organization (1998) Quality control methods for medicinal plant materials. New York pp 122.

Zhao C-C, Jiang G-H, Eun, J-B (2017) Optimization of drying process for squid-laver snack by a combined method of fuzzy synthetic and response surface methodology. J Food Qual 2017(Article ID 9761356): 1-10. https://doi.org/10.1155/2017/9761356

Zlatanović I, Komatina M, Antonijević D (2013). Low-temperature convective drying of apple cubes. Appl Thermal Eng 53: 114-123. 
Table 1. Experimental range and levels of the variables with the experimental design using rotatable central composite design for chilli pepper drying

\begin{tabular}{|c|c|c|c|c|c|}
\hline Dependable Variable & -2 & -1 & 0 & +1 & +2 \\
\hline Air Velocity $\left(X_{1}\right)(\mathrm{m} / \mathrm{s})$ & 0.0 & 0.5 & 1.0 & 1.5 & 2.0 \\
\hline Relative Humidity $\left(\mathrm{X}_{2}\right)(\%)$ & 60 & 65 & 70 & 75 & 80 \\
\hline Drying Temperature $\left(X_{3}\right){ }^{\circ} \mathrm{C}$ & 40 & 50 & 60 & 70 & 80 \\
\hline Drying Time $\left(X_{4}\right)(\mathrm{min})$ & 90 & 180 & 270 & 360 & 450 \\
\hline \multirow[t]{3}{*}{ Run } & Air & Relative & Drying & Drying & \\
\hline & $\begin{array}{c}\text { Velocity } \\
(\mathrm{m} / \mathrm{s})\end{array}$ & $\begin{array}{c}\text { Humidity } \\
(\%)\end{array}$ & $\begin{array}{l}\text { Temperature } \\
\left({ }^{\mathrm{o}} \mathrm{C}\right)\end{array}$ & $\begin{array}{l}\text { Time } \\
(\min )\end{array}$ & \\
\hline & $X_{1}$ & $X_{2}$ & $X_{3}$ & $X_{4}$ & \\
\hline 1 & 0.5 & 65 & 50 & 180 & \\
\hline 2 & 1.5 & 65 & 50 & 180 & \\
\hline 3 & 0.5 & 75 & 50 & 180 & \\
\hline 4 & 1.5 & 75 & 50 & 180 & \\
\hline 5 & 0.5 & 65 & 70 & 180 & \\
\hline 6 & 1.5 & 65 & 70 & 180 & \\
\hline 7 & 0.5 & 75 & 70 & 180 & \\
\hline 8 & 1.5 & 75 & 70 & 180 & \\
\hline 9 & 0.5 & 65 & 50 & 360 & \\
\hline 10 & 1.5 & 65 & 50 & 360 & \\
\hline 11 & 0.5 & 75 & 50 & 360 & \\
\hline 12 & 1.5 & 75 & 50 & 360 & \\
\hline 13 & 0.5 & 65 & 70 & 360 & \\
\hline 14 & 1.5 & 65 & 70 & 360 & \\
\hline 15 & 0.5 & 75 & 70 & 360 & \\
\hline 16 & 1.5 & 75 & 70 & 360 & \\
\hline 17 & 0.0 & 70 & 60 & 270 & \\
\hline 18 & 2.0 & 70 & 60 & 270 & \\
\hline 19 & 1.0 & 60 & 60 & 270 & \\
\hline 20 & 1.0 & 80 & 60 & 270 & \\
\hline 21 & 1.0 & 70 & 40 & 270 & \\
\hline 22 & 1.0 & 70 & 80 & 270 & \\
\hline 23 & 1.0 & 70 & 60 & 90 & \\
\hline 24 & 1.0 & 70 & 60 & 450 & \\
\hline 25 & 1.0 & 70 & 60 & 270 & \\
\hline 26 & 1.0 & 70 & 60 & 270 & \\
\hline 27 & 1.0 & 70 & 60 & 270 & \\
\hline 28 & 1.0 & 70 & 60 & 270 & \\
\hline 29 & 1.0 & 70 & 60 & 270 & \\
\hline 30 & 1.0 & 70 & 60 & 270 & \\
\hline
\end{tabular}


Table 2. Values of dried chilli pepper product moisture content, protein content, carbohydrate content and total plate count

\begin{tabular}{|c|c|c|c|c|c|c|c|c|c|c|c|c|}
\hline \multirow[t]{3}{*}{ Run } & \multicolumn{4}{|c|}{ Factors } & \multicolumn{8}{|c|}{ Response } \\
\hline & \multirow{2}{*}{$\begin{array}{l}\text { A.V } \\
(\mathrm{m} / \mathrm{s})\end{array}$} & R.H & \multicolumn{2}{|c|}{ Temp Time } & \multicolumn{2}{|c|}{ PMC (kg) } & \multicolumn{2}{|c|}{$\mathrm{PC}(\%)$} & \multicolumn{2}{|c|}{$\mathrm{CC}(\%)$} & \multicolumn{2}{|c|}{ TPC (cfu/g) } \\
\hline & & $(\%)$ & $\left({ }^{\circ} \mathrm{C}\right)$ & $(\min )$ & Expt & Pred & Expt & Pred & Expt & Pred & Expt & Pred \\
\hline 1 & 0.5 & 65 & 50 & 180 & 3.82 & 3.78 & 9.75 & 9.85 & 33.44 & 33.50 & 46.80 & 46.17 \\
\hline 2 & .5 & 65 & 50 & 180 & 3.76 & 3.93 & 9.82 & 9.65 & 33.52 & 33.42 & 46.30 & 47.58 \\
\hline 3 & 0.5 & 75 & 50 & 180 & 4.10 & 4.11 & 9.66 & 9.67 & 33.33 & 33.29 & 47.30 & 47.42 \\
\hline 4 & 1.5 & 75 & 50 & 180 & 3.79 & 3.88 & 9.78 & 9.83 & 33.50 & 33.52 & 46.50 & 46.43 \\
\hline 5 & .5 & 65 & 70 & 180 & 3.69 & 3.64 & 10.00 & 10.06 & 33.77 & 33.82 & 43.90 & 43.85 \\
\hline 6 & 1.5 & 65 & 70 & 180 & 3.53 & 3.46 & 10.26 & 10.36 & 34.20 & 34.27 & 42.80 & 42.22 \\
\hline 7 & .5 & 75 & 70 & 80 & 3.72 & 3.94 & 9.89 & 9.73 & 33.69 & 33.62 & 45.10 & 45.70 \\
\hline 8 & 1.5 & 75 & 70 & 180 & 3.55 & 3.39 & 10.22 & 10.38 & 34.17 & 34.38 & 43.10 & 42.67 \\
\hline 9 & 0.5 & 65 & 50 & 360 & 2.72 & 2.81 & 10.92 & 10.86 & 35.11 & 35.01 & 40.10 & 40.20 \\
\hline 10 & 1.5 & 65 & 50 & 360 & 2.60 & 2.42 & 10.98 & 11.08 & 35.35 & 35.40 & 38.80 & 38.67 \\
\hline 11 & 0.5 & 75 & 50 & 360 & 3.49 & 3.61 & 10.40 & 10.24 & 34.38 & 34.29 & 42.40 & 43.45 \\
\hline 12 & 1.5 & 75 & 50 & 360 & 2.85 & 2.84 & 10.77 & 10.81 & 34.92 & 34.99 & .80 & 40.52 \\
\hline 13 & 0.5 & 65 & 70 & 360 & 1.60 & 1.56 & 12.33 & 12.22 & 36.42 & 36.38 & 33.20 & 33.73 \\
\hline 14 & 1.5 & 65 & 70 & 360 & 0.92 & 0.84 & 12.84 & 12.93 & 37.14 & 37.30 & 30.60 & 30.15 \\
\hline 15 & 0.5 & 75 & 70 & 360 & 2.57 & 2.34 & 11.18 & 11.44 & 35.45 & 35.66 & 38.20 & 37.58 \\
\hline 16 & 1.5 & 75 & 70 & 360 & 1.16 & 1.24 & 12.66 & 12.50 & 36.97 & 36.90 & 31.50 & 32.60 \\
\hline 17 & 0.0 & 70 & 60 & 270 & 3.99 & 3.94 & 9.70 & 9.75 & 33.36 & 33.42 & 47.00 & 46.52 \\
\hline 18 & 2.0 & 70 & 60 & 270 & 2.92 & 2.99 & 10.70 & 10.62 & 34.74 & 34.58 & 41.60 & 41.95 \\
\hline 19 & 1.0 & 60 & 60 & 270 & 2.08 & 2.17 & 11.30 & 11.26 & 35.90 & 35.87 & 37.00 & 37.53 \\
\hline 20 & 1.0 & 80 & 60 & 270 & 2.96 & 2.89 & 10.66 & 10.66 & 35.33 & 35.26 & 41.90 & 41.23 \\
\hline 21 & 1.0 & 70 & 40 & 270 & 3.72 & 3.59 & 9.89 & 9.95 & 33.69 & 33.80 & 45.10 & 44.95 \\
\hline 22 & 1.0 & 70 & 80 & 270 & 1.69 & 1.85 & 11.96 & 11.86 & 36.24 & 36.03 & 34.70 & 34.72 \\
\hline 23 & 1.0 & 70 & 60 & 90 & 4.88 & 4.79 & 9.33 & 9.28 & 32.49 & 32.44 & 48.60 & 49.05 \\
\hline 24 & 1.0 & 70 & 60 & 450 & 1.56 & 1.67 & 12.40 & 12.42 & 36.52 & 36.47 & 33.60 & 33.02 \\
\hline 25 & 1.0 & 70 & 60 & 270 & 2.99 & 2.99 & 10.62 & 10.62 & 34.68 & 34.68 & 42.10 & 42.10 \\
\hline 26 & 1.0 & 70 & 60 & 270 & 2.99 & 2.99 & 10.62 & 10.62 & 34.68 & 34.68 & 42.10 & 42.10 \\
\hline 27 & 1.0 & 70 & 60 & 270 & 2.99 & 2.99 & 10.62 & 10.62 & 34.68 & 34.68 & 42.10 & 42.10 \\
\hline 28 & 1.0 & 70 & 60 & 270 & 2.99 & 2.99 & 10.62 & 10.62 & 34.68 & 34.68 & 42.10 & 42.10 \\
\hline 29 & 1.0 & 70 & 60 & 270 & 2.99 & 2.99 & 10.62 & 10.62 & 34.68 & 34.68 & 42.10 & 42.10 \\
\hline 30 & 1.0 & 70 & 60 & 270 & 2.99 & 2.99 & 10.62 & 10.62 & 34.68 & 34.68 & 42.10 & 42.10 \\
\hline
\end{tabular}


Table 3. Coefficient of the regression model for product moisture content, protein content, carbohydrate content and total plate count for dried chilli pepper

\begin{tabular}{|l|c|c|c|c|}
\hline \multirow{2}{*}{ Variable } & \multicolumn{4}{|c|}{ Coefficient Estimate of the Regression Model for the Response } \\
\cline { 2 - 5 } & PMC & 10.62 & 34.68 & TPC \\
\hline$\beta_{o}$ & 2.99 & 0.22 & 0.29 & -1.14 \\
\hline$\beta_{1}$ & -0.24 & -0.15 & -0.15 & 0.92 \\
\hline$\beta_{2}$ & 0.18 & 0.48 & 0.56 & -2.56 \\
\hline$\beta_{3}$ & -0.44 & 0.78 & 1.01 & -4.01 \\
\hline$\beta_{4}$ & -0.78 & -0.11 & -0.17 & 0.53 \\
\hline$\beta_{11}$ & 0.12 & 0.086 & 0.22 & -0.68 \\
\hline$\beta_{22}$ & -0.11 & 0.072 & 0.059 & -0.57 \\
\hline$\beta_{33}$ & -0.068 & 0.057 & -0.056 & -0.27 \\
\hline$\beta_{44}$ & 0.060 & 0.088 & 0.078 & -0.35 \\
\hline$\beta_{12}$ & -0.094 & 0.12 & 0.13 & -0.51 \\
\hline$\beta_{13}$ & -0.081 & 0.10 & 0.12 & -0.49 \\
\hline$\beta_{14}$ & -0.13 & -0.039 & 0.0025 & 0.15 \\
\hline$\beta_{23}$ & -0.0044 & -0.11 & -0.14 & 0.50 \\
\hline$\beta_{24}$ & 0.12 & 0.29 & 0.26 & -1.04 \\
\hline$\beta_{34}$ & -0.28 & & & \\
\hline
\end{tabular}


Table 4. ANOVA for response of product moisture content, protein content, carbohydrate content and total plate count of dried chilli pepper

\begin{tabular}{|c|c|c|c|c|c|c|c|c|c|c|c|c|c|c|c|c|}
\hline Source & \multicolumn{4}{|c|}{ Product Moisture Content } & \multicolumn{4}{|c|}{ Protein Content } & \multicolumn{4}{|c|}{ Carbohydrate Content } & \multicolumn{4}{|c|}{ Total Plate Count } \\
\hline$X_{1}$ & 1.35 & 1.35 & 61.6 & $<0.0001^{*}$ & 1.13 & 1.13 & 59.2 & $<0.0001^{*}$ & 2.01 & 2.01 & 109.4 & $<0.0001^{*}$ & 31.3 & 31.3 & 74.2 & $<0.0001^{*}$ \\
\hline$X_{2}$ & 0.79 & 0.79 & 36.0 & $<0.0001^{*}$ & 0.55 & 0.55 & 28.7 & $<0.0001^{*}$ & 0.56 & 0.56 & 30.8 & $<0.0001^{*}$ & 20.5 & 20.5 & 48.7 & $0.0037^{*}$ \\
\hline$X_{3}$ & 4.55 & 4.55 & 207.8 & $<0.0001^{*}$ & 5.45 & 5.45 & 286.6 & $<0.0001^{*}$ & 7.44 & 7.44 & 405.2 & $<0.0001^{*}$ & 157.1 & 157.1 & 372.3 & $<0.0001^{*}$ \\
\hline$X_{4}$ & 14.6 & 14.6 & 664.7 & $<0.0001^{*}$ & 14.8 & 14.8 & 777.2 & $<0.0001^{*}$ & 24.4 & 24.4 & 1327 & $<0.0001^{*}$ & 385.6 & 385.6 & 914.0 & $<0.0001^{*}$ \\
\hline$X_{1}^{2}$ & 0.39 & 0.39 & 17.8 & $0.0008^{*}$ & 0.33 & 0.33 & 17.2 & $0.0009^{*}$ & 0.79 & 0.79 & 43.1 & $<0.0001^{*}$ & 7.80 & 7.80 & 18.5 & $0.0006^{*}$ \\
\hline$X_{4}^{2}$ & 0.100 & 0.100 & 4.56 & $0.0497^{*}$ & 0.089 & \begin{tabular}{|l|}
0.089 \\
\end{tabular} & 4.66 & $0.0474^{*}$ & 0.086 & 0.086 & 4.69 & $0.0468^{*}$ & 1.95 & 1.95 & 4.62 & $0.0483^{*}$ \\
\hline$X_{1} X_{2}$ & 0.14 & 0.14 & 6.51 & $0.0221^{*}$ & 0.12 & 0.12 & 6.44 & $0.0228^{*}$ & 0.096 & 0.096 & 5.24 & $0.0371^{*}$ & 1.96 & 1.96 & 4.65 & $0.0478^{*}$ \\
\hline$X_{1} X_{3}$ & 0.10 & 0.10 & 4.75 & $0.0456^{*}$ & 0.24 & 0.24 & 12.6 & $0.0029^{*}$ & 0.28 & 0.28 & 15.3 & $0.0014^{*}$ & 4.20 & 4.20 & 9.96 & $0.0065^{*}$ \\
\hline$X_{1} X_{4}$ & 0.29 & 0.29 & 13.2 & $0.0025^{*}$ & 0.17 & 0.17 & 8.83 & $0.0095^{*}$ & 0.22 & 0.22 & 11.8 & $0.0152^{*}$ & 3.80 & 3.80 & 9.01 & $0.0089^{*}$ \\
\hline$X_{2} X_{3}$ & $3 \mathrm{E}-4$ & $3 \mathrm{E}-4$ & 0.014 & 0.9074 & 0.024 & 0.024 & 1.26 & 0.2788 & $1 \mathrm{E}-4$ & $1 \mathrm{E}-4$ & 0.005 & 0.9421 & 0.36 & 0.36 & 0.85 & 0.3702 \\
\hline Lack of Fit & 0.33 & 0.033 & & & 0.29 & 0.029 & & & 0.28 & 0.028 & & & 6.33 & 0.63 & & \\
\hline Pure Error & 0.000 & 0.000 & & & 0.000 & 0.000 & & & 0.000 & 0.000 & & & 0.000 & 0.000 & & \\
\hline Cor Total & 24.69 & & & & 25.12 & & & & 39.29 & & & & 665.7 & & & \\
\hline$R^{2}$ & \multicolumn{4}{|c|}{0.9867} & \multicolumn{4}{|c|}{0.9886} & \multicolumn{4}{|c|}{0.9930} & \multicolumn{4}{|c|}{0.9905} \\
\hline Adj. $R^{2}$ & \multicolumn{4}{|c|}{0.9743} & \multicolumn{4}{|c|}{0.9780} & \multicolumn{4}{|c|}{0.9865} & \multicolumn{4}{|c|}{0.9815} \\
\hline Pred. $R^{2}$ & \multicolumn{4}{|c|}{0.9234} & \multicolumn{4}{|c|}{0.9345} & \multicolumn{4}{|c|}{0.9596} & \multicolumn{4}{|c|}{0.9452} \\
\hline Adeq. Pre & \multicolumn{4}{|c|}{37.703} & \multicolumn{4}{|c|}{37.425} & \multicolumn{4}{|c|}{50.726} & \multicolumn{4}{|c|}{41.151} \\
\hline
\end{tabular}

Note: $\mathrm{SS}=$ Sum of Squares; MS = Mean Square; Adj. = Adjusted; Pred. = Predicted; Adeq. Pre. $=$ Adequate Precision; $*$ Significant at $p<0.05$ 
Table 5. Statistical validation and the drying constant of the tested drying models at different drying conditions

\begin{tabular}{|c|c|c|c|c|c|c|c|c|c|c|c|c|c|c|c|c|}
\hline \multirow{2}{*}{$\begin{array}{l}\text { Drying Conditions } \\
\text { Air Velocity }\end{array}$} & \multicolumn{2}{|l|}{$\begin{array}{c}k \\
R M S E\end{array}$} & & \multicolumn{4}{|c|}{$\begin{array}{lll}a & k & R^{2} \\
\text { RMSE } & & \end{array}$} & \multirow{2}{*}{\multicolumn{3}{|c|}{$\begin{array}{l}a \\
R M S E\end{array}$}} & \multicolumn{2}{|l|}{$R^{2}$} & \multirow{2}{*}{\multicolumn{2}{|c|}{$n \quad R^{2}$}} & \multirow[t]{2}{*}{ RMSE } \\
\hline & & & & & & & & & & & & & & & & \\
\hline 0.3 & $1.0 \mathrm{E}-4$ & 1.62 & 0.976 & 0.027 & 1.39 & 0.0050 & 0.956 & 0.074 & 1.10 & $1 \mathrm{E}-06$ & 0.0005 & 0.955 & 0.078 & 0.0036 & 0.924 & 0.097 \\
\hline 1.0 & $2.1 \mathrm{E}-4$ & 1.51 & 0.978 & 0.030 & 1.24 & 0.0051 & 0.967 & 0.068 & 1.09 & $1 \mathrm{E}-06$ & 0.0030 & 0.946 & 0.065 & 0.0037 & 0.948 & 0.079 \\
\hline 1.3 & $2.4 \mathrm{E}-4$ & 1.48 & 0.984 & 0.037 & 1.10 & 0.0057 & 0.953 & 0.064 & 1.08 & $1 \mathrm{E}-06$ & 0.0050 & 0.953 & 0.064 & 0.0046 & 0.944 & 0.069 \\
\hline 1.8 & $2.7 \mathrm{E}-4$ & 1.42 & 0.997 & 0.016 & 1.08 & 0.0063 & 0.964 & 0.058 & 1.05 & $1 \mathrm{E}-06$ & 0.0057 & 0.964 & 0.058 & 0.0052 & 0.951 & 0.067 \\
\hline 2.0 & $3.1 \mathrm{E}-4$ & 1.39 & 0.981 & 0.034 & 1.07 & 0.0075 & 0.949 & 0.055 & 1.02 & 1E-06 & 0.0075 & 0.949 & 0.055 & 0.0070 & 0.941 & 0.059 \\
\hline \multicolumn{17}{|l|}{ R. Humidity } \\
\hline 65 & $1.78 \mathrm{E}-4$ & 1.40 & 0.996 & 0.017 & 1.08 & 0.0081 & 0.957 & 0.057 & 1.03 & 1E-06 & 0.0076 & 0.947 & 0.064 & 0.0734 & 0.944 & 0.065 \\
\hline 70 & $1.77 \mathrm{E}-4$ & 1.50 & 0.995 & 0.020 & 1.09 & 0.0076 & 0.965 & 0.053 & 1.08 & $1 \mathrm{E}-06$ & 0.0072 & 0.965 & 0.053 & 0.0069 & 0.951 & 0.062 \\
\hline 75 & $1.76 \mathrm{E}-4$ & 1.52 & 0.998 & 0.013 & 1.10 & 0.0066 & 0.942 & 0.072 & 1.09 & 1E-06 & 0.0066 & 0.945 & 0.072 & 0.0059 & 0.924 & 0.083 \\
\hline 80 & $1.62 \mathrm{E}-4$ & 1.60 & 0.989 & 0.032 & 1.10 & 0.0061 & 0.959 & 0.063 & 1.09 & $1 \mathrm{E}-06$ & 0.0061 & 0.959 & 0.062 & 0.0056 & 0.949 & 0.069 \\
\hline 85 & $1.40 \mathrm{E}-4$ & 1.79 & 0.993 & 0.026 & 1.13 & 0.0047 & 0.971 & 0.053 & 1.26 & 1E-06 & 0.0047 & 0.971 & 0.053 & 0.0043 & 0.961 & 0.061 \\
\hline \multicolumn{17}{|l|}{ Temperature } \\
\hline 40 & $4.0 \mathrm{E}-4$ & 1.64 & 0.982 & 0.027 & 1.45 & 0.0035 & 0.941 & 0.074 & 1.09 & $1 \mathrm{E}-05$ & 0.0056 & 0.954 & 0.078 & 0.0041 & 0.925 & 0.097 \\
\hline 50 & $4.3 \mathrm{E}-4$ & 1.60 & 0.984 & 0.030 & 1.43 & 0.0043 & 0.954 & 0.068 & 1.08 & 1E-05 & 0.0059 & 0.936 & 0.065 & 0.0046 & 0.935 & 0.079 \\
\hline 60 & $6.3 \mathrm{E}-4$ & 1.53 & 0.979 & 0.037 & 1.08 & 0.0054 & 0.945 & 0.064 & 1.09 & 1E-05 & 0.0068 & 0.947 & 0.064 & 0.0047 & 0.935 & 0.069 \\
\hline 70 & $8.3 \mathrm{E}-4$ & 1.26 & 0.994 & 0.016 & 1.08 & 0.0056 & 0.954 & 0.058 & 1.09 & $1 \mathrm{E}-05$ & 0.0068 & 0.953 & 0.058 & 0.0056 & 0.932 & 0.067 \\
\hline
\end{tabular}




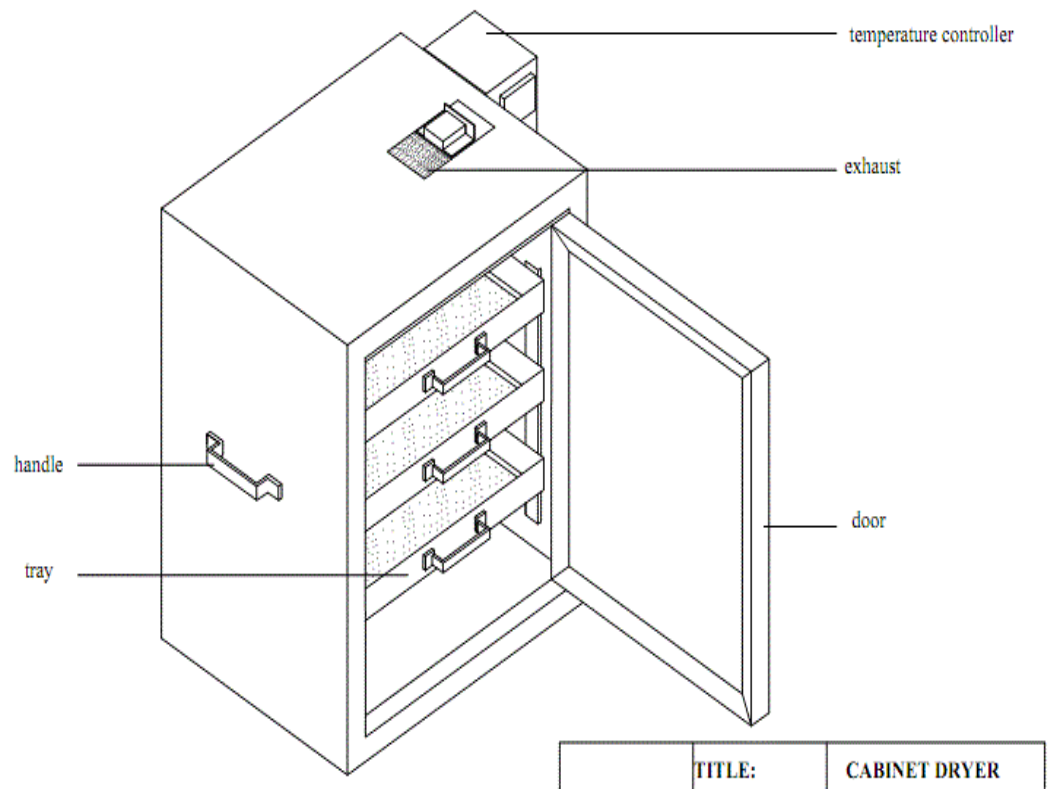

Fig. 1. A cabinet dryer for the drying of chilli pepper 


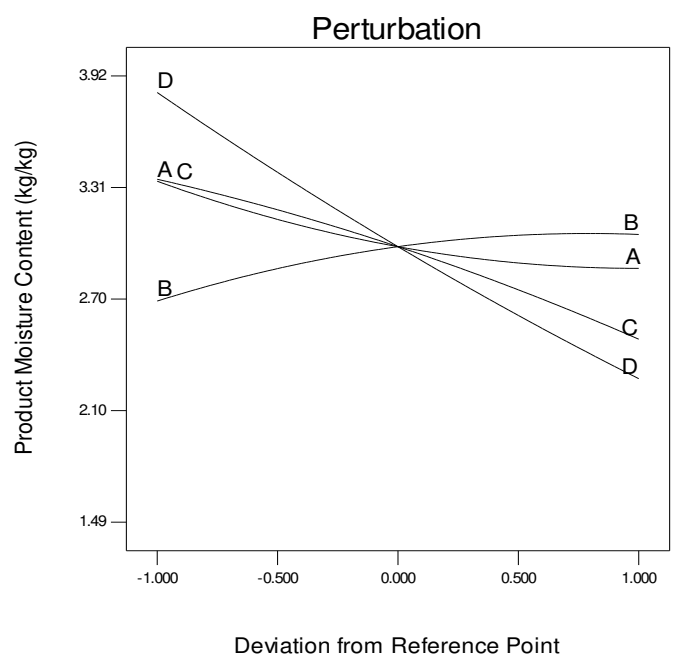

(a)

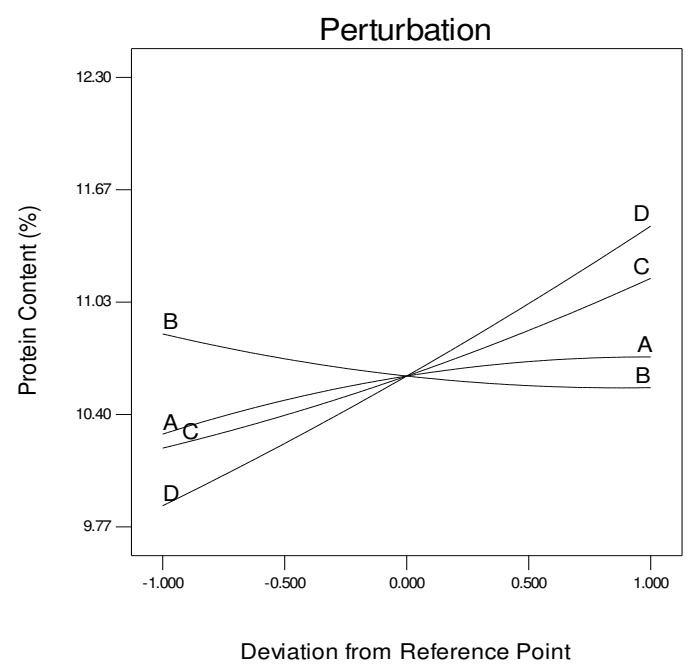

(c)

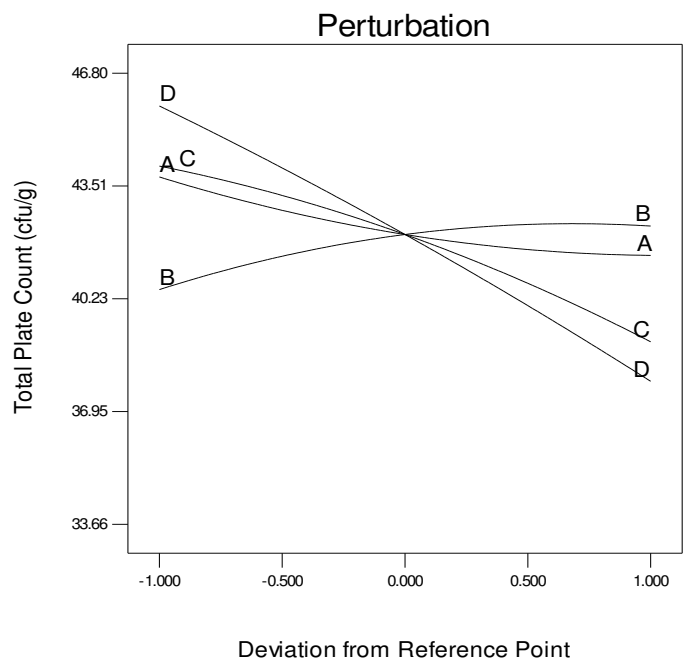

(b)

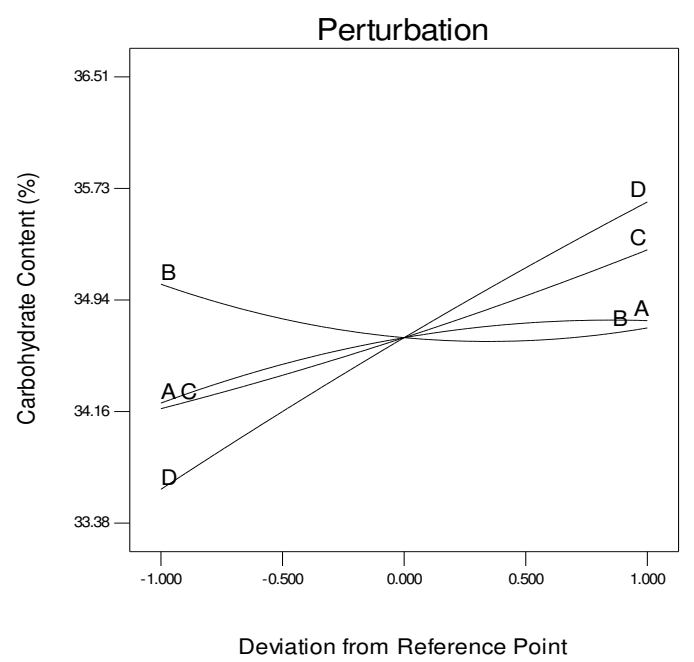

(d)

Fig. 2. Perturbation plot representing the deviation from reference point for (a) Product moisture content, (b) Total plate count, (c) Protein content, and (d) Carbohydrate content 


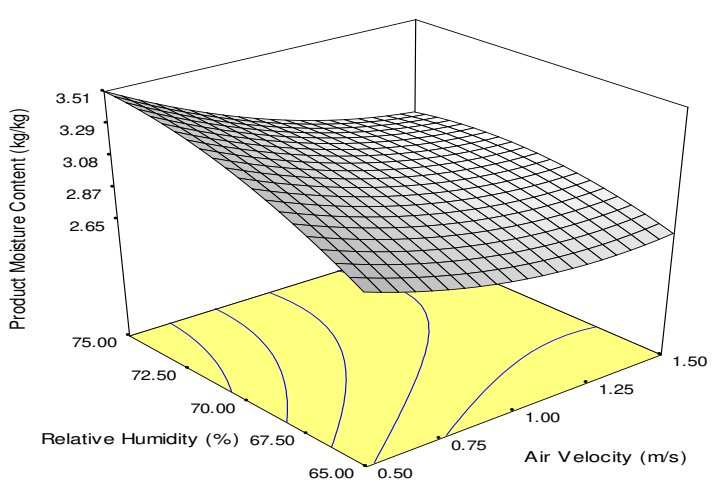

(a)

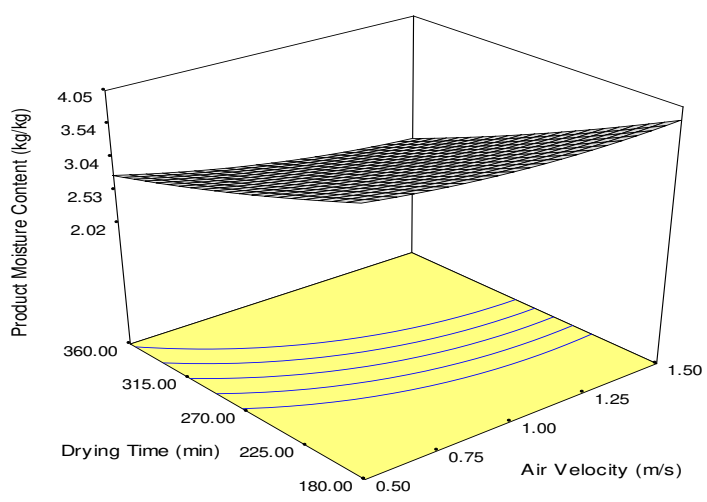

(c)

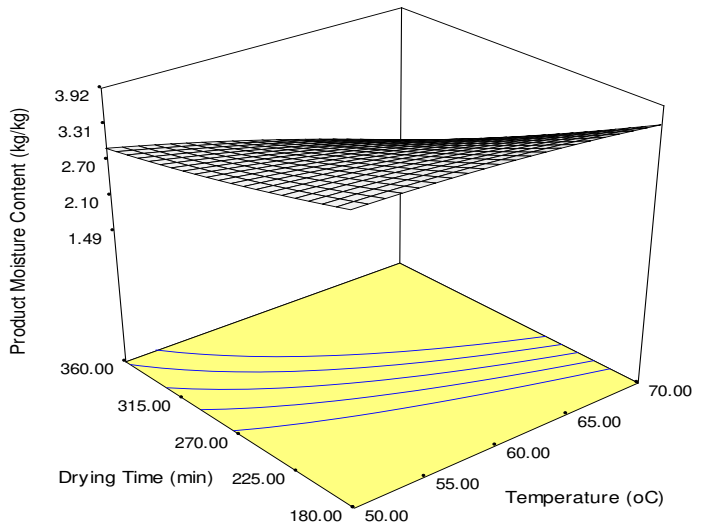

(e)

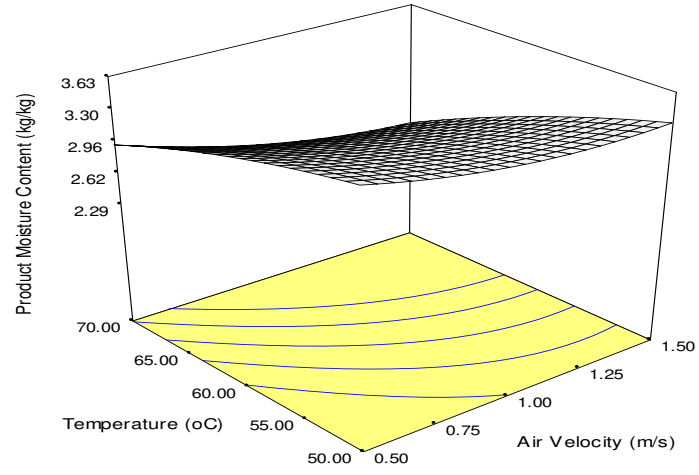

(b)

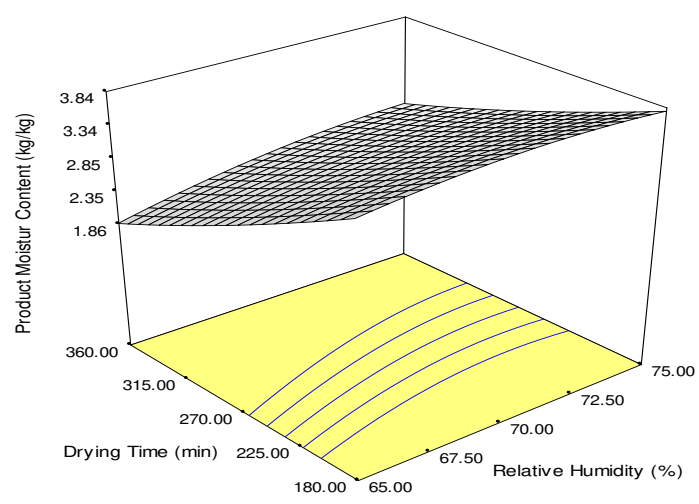

(d)

Fig. 3. Three dimensional (3D) response surface plot indicating the: (a) interaction effect of relative humidity and air velocity on $\mathrm{PMC}$, (b) interaction effect of temperature and air velocity on PMC, (c) interaction effect of drying time and air velocity on PMC, (d) interaction effect of drying time and relative humidity on PMC, and (e) interaction effect of drying time and temperature on PMC of the dried chilli pepper. 


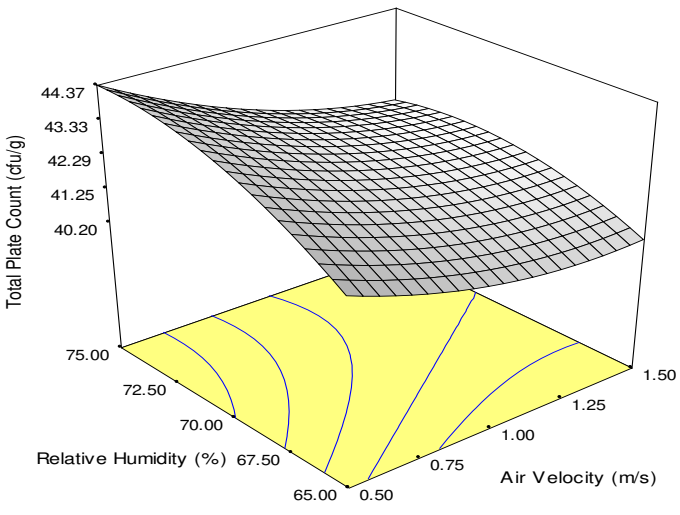

(a)

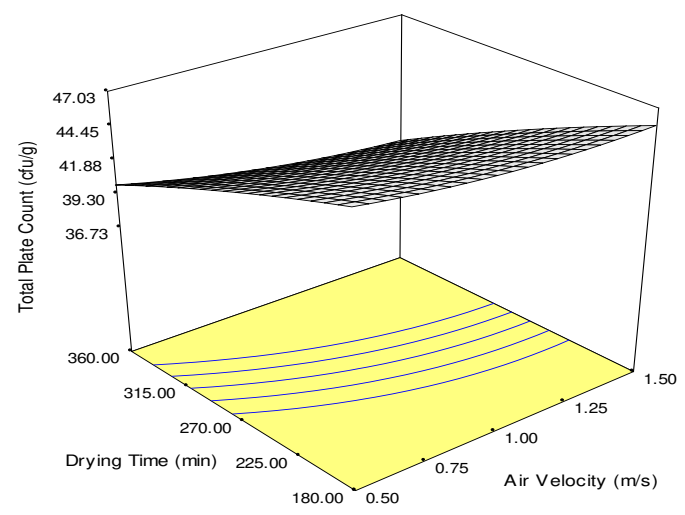

(c)

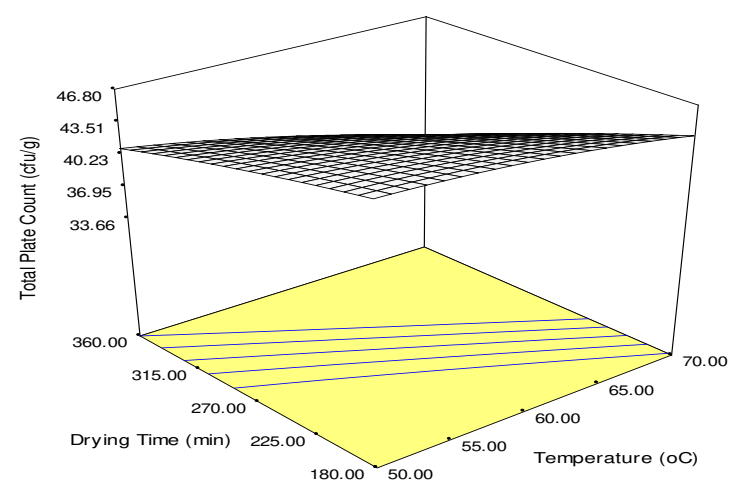

(e)

Fig. 4. Three dimensional (3D) response surface plot indicating the: (a) interaction effect of relative humidity and air velocity on TPC, (b) interaction effect of temperature and air velocity on TPC, (c) interaction effect of drying time and air velocity on TPC, (d) interaction effect of drying time and relative humidity on TPC, and (e) interaction effect of drying time and temperature on TPC of the dried chilli pepper.

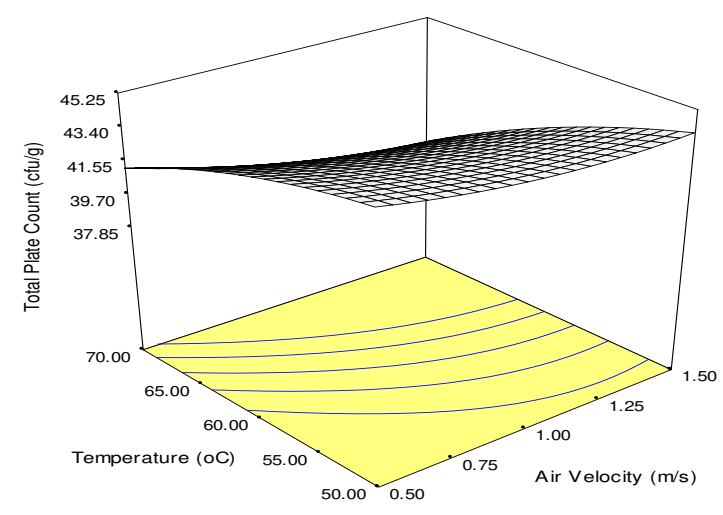

(b)

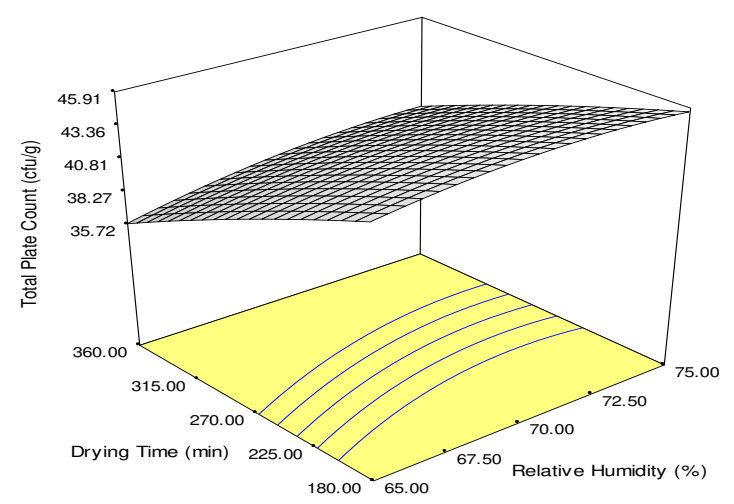

(d) 


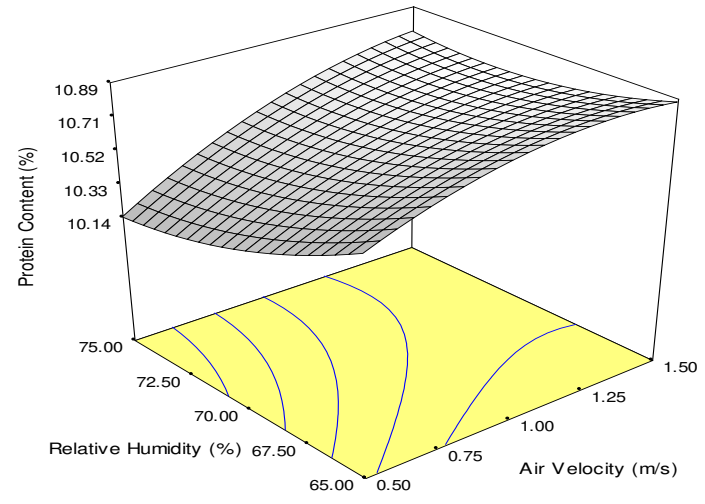

(a)

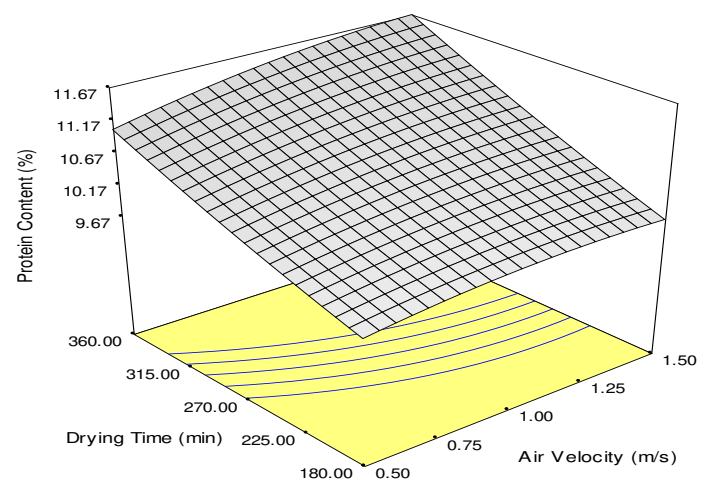

(c)

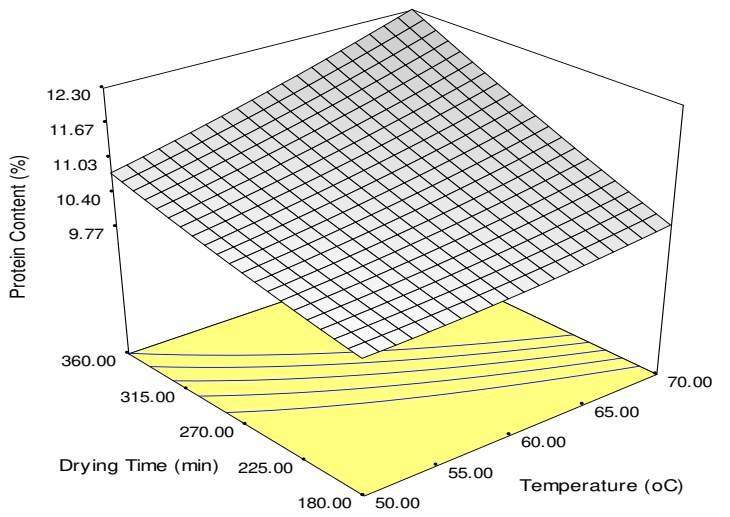

(e)

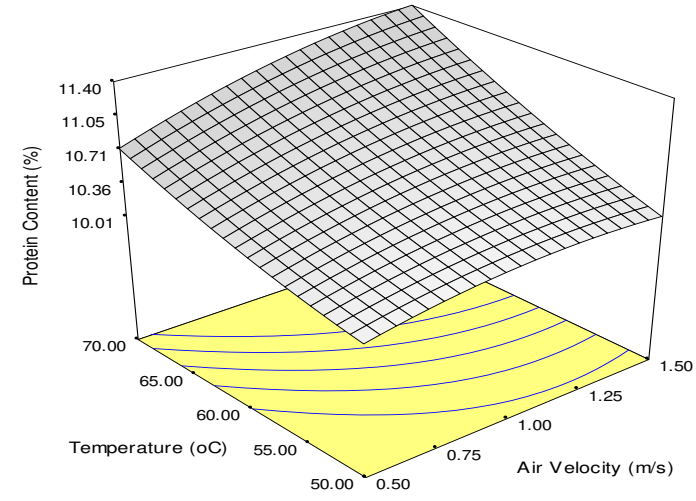

(b)

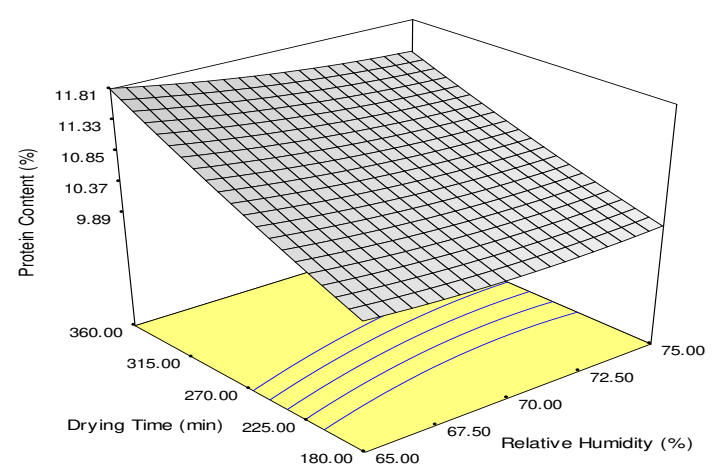

(d)

Fig. 5. Three dimensional (3D) response surface plot indicating the: (a) interaction effect of relative humidity and air velocity on $\mathrm{PC},(\mathrm{b})$ interaction effect of temperature and air velocity on $\mathrm{PC}$, (c) interaction effect of drying time and air velocity on PC, (d) interaction effect of drying time and relative humidity on PC, and (e) interaction effect of drying time and temperature on PC of the dried chilli pepper. 


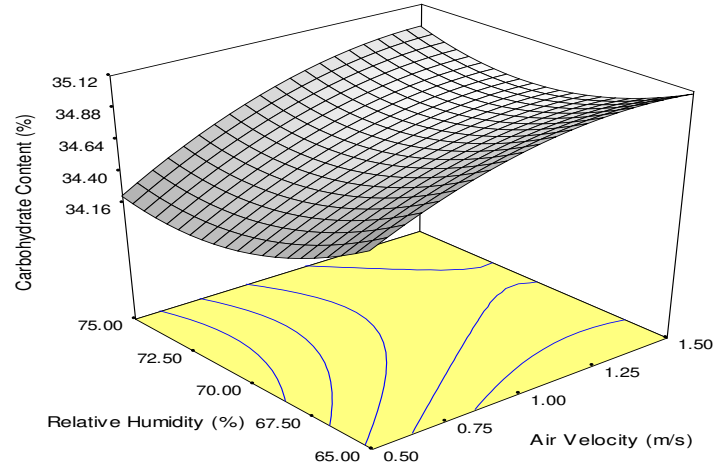

(a)

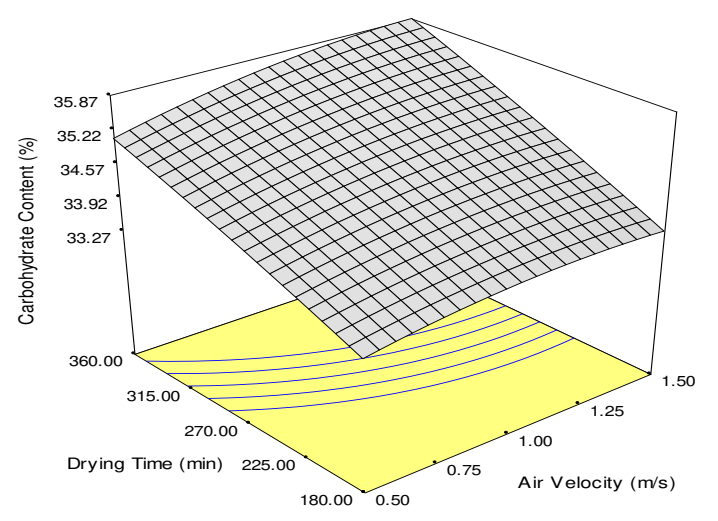

(c)

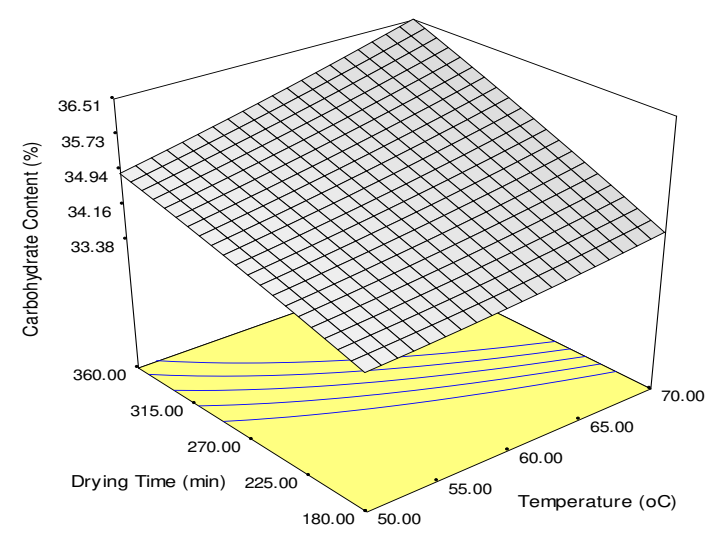

(e)

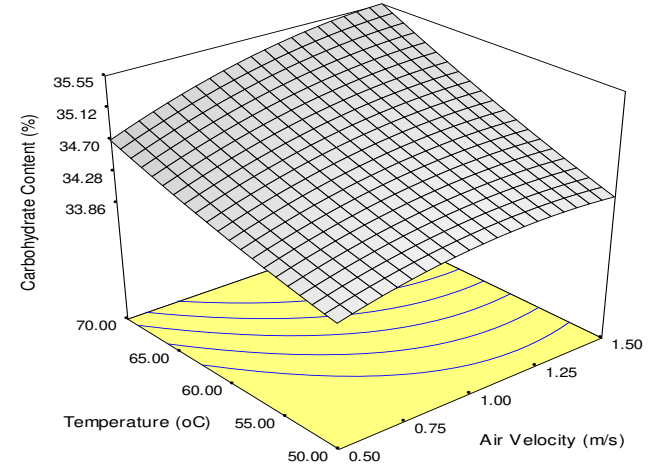

(b)

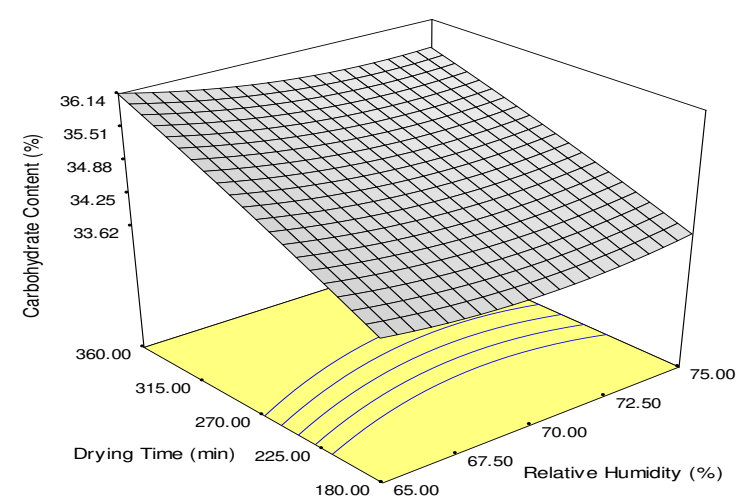

(d)

Fig. 6. Three dimensional (3D) response surface plot indicating the: (a) interaction effect of relative humidity and air velocity on $\mathrm{CC}$, (b) interaction effect of temperature and air velocity on $\mathrm{CC}$, (c) interaction effect of drying time and air velocity on CC, (d) interaction effect of drying time and relative humidity on $\mathrm{CC}$, and (e) interaction effect of drying time and temperature on $\mathrm{CC}$ of the dried chilli pepper. 


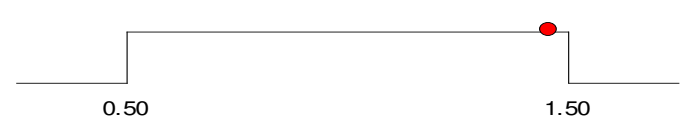

Air Velocity $=1.46$

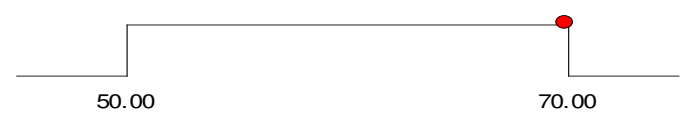

Temperature $=69.98$

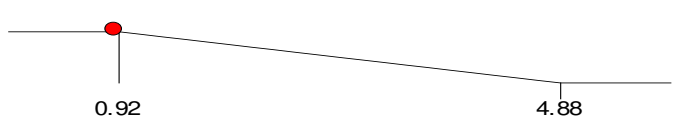

$\mathrm{PMC}=0.90$

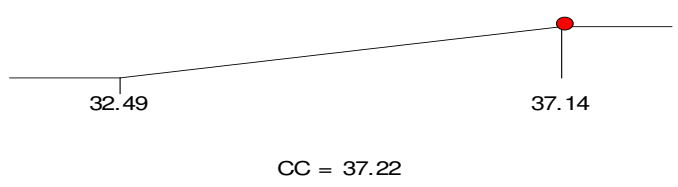

Desirability $=1.000$

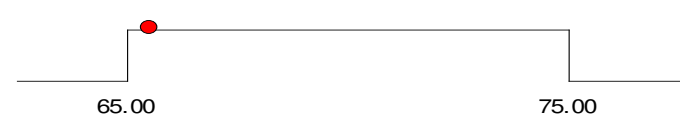

Relative Humidity $=65.57$

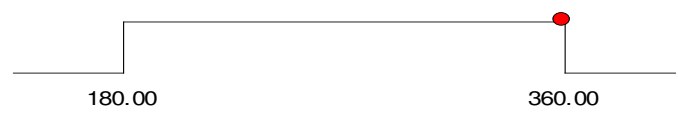

Drying Time $=359.96$

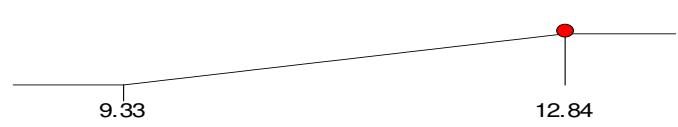

$P C=12.87$

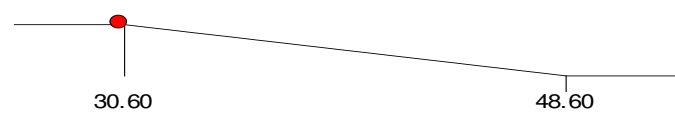

$\mathrm{TPC}=30.51$

Fig. 7. Ramps (desirability plot) showing predicted optimum values for the drying process conditions and predicted optimum values for the corresponding responses (quality attributes). 
Figures

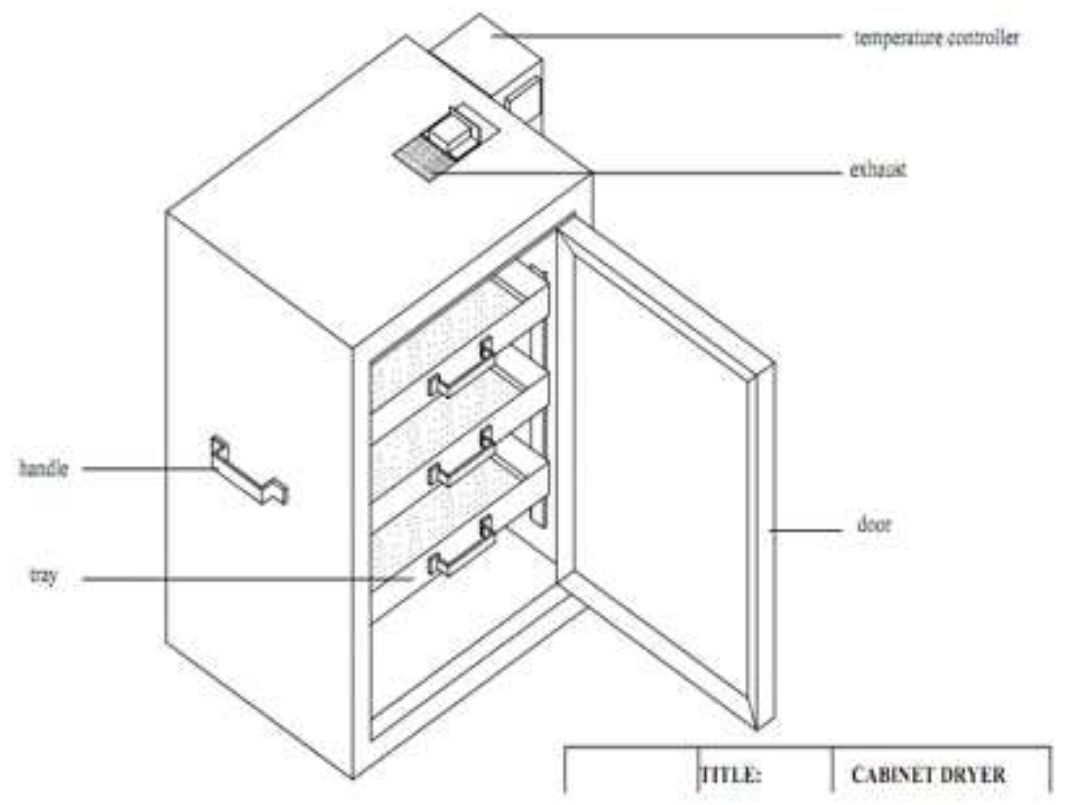

Figure 1

A cabinet dryer for the drying of chilli pepper 


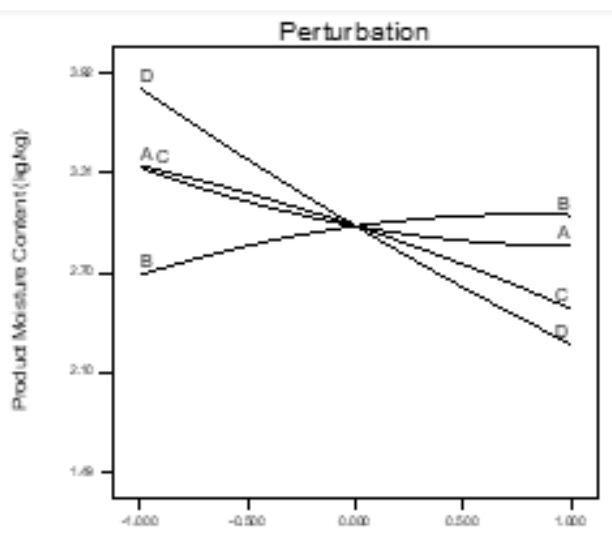

Deviation from Reterence Point

(a)

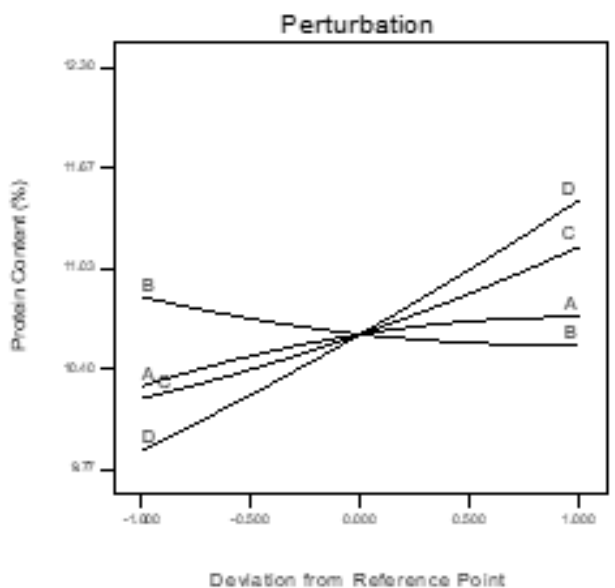

(c)

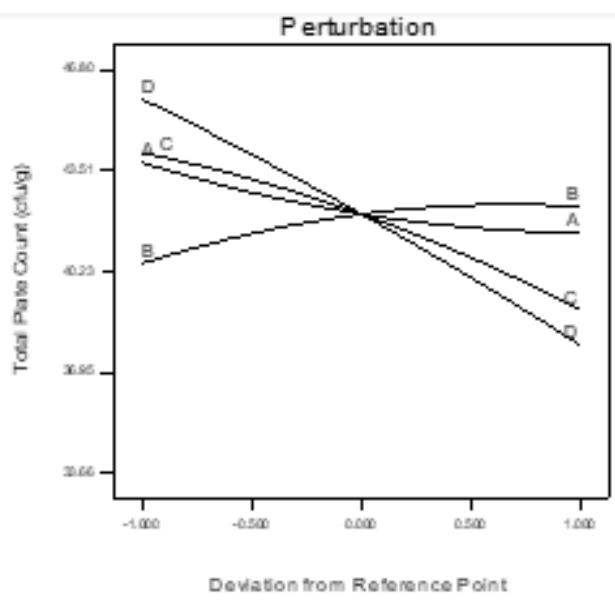

(b)

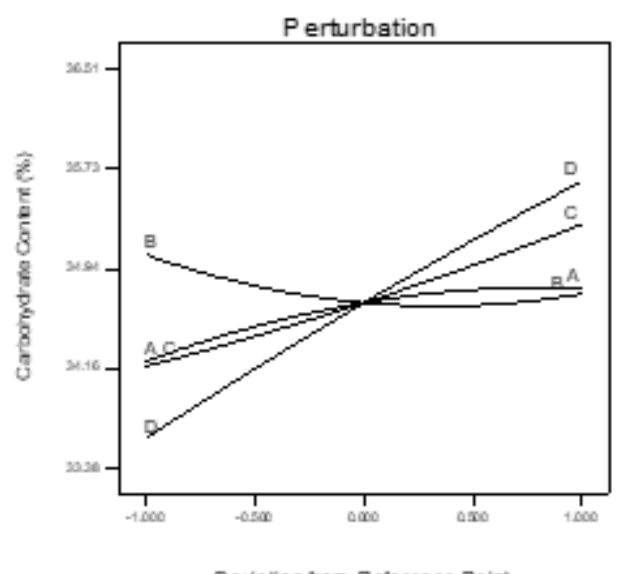

Deviaton from Reterence Point (d)

\section{Figure 2}

Perturbation plot representing the deviation from reference point for (a) Product moisture content, (b) Total plate count, (c) Protein content, and (d) Carbohydrate content 


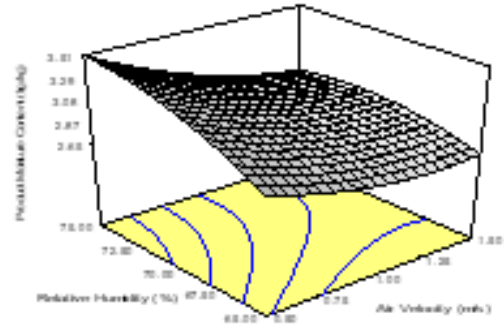

(a)

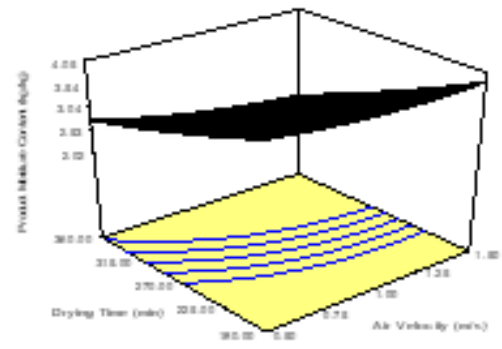

(c)

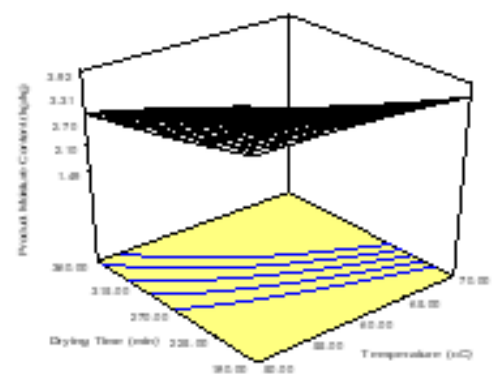

(e)

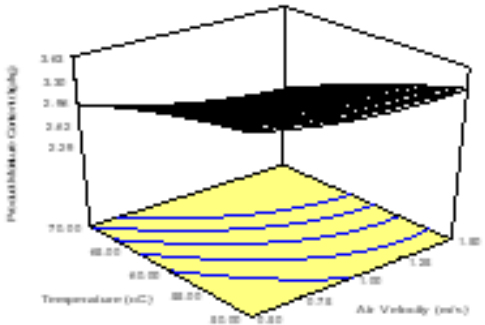

(b)

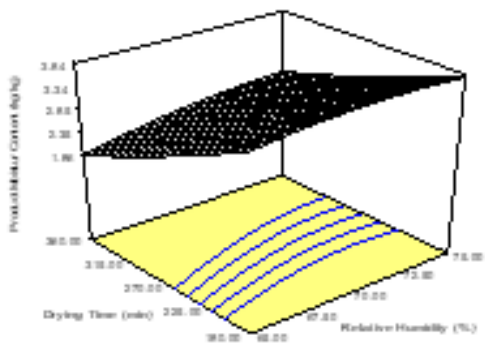

(d)

\section{Figure 3}

Three dimensional (3D) response surface plot indicating the: (a) interaction effect of relative humidity and air velocity on $\mathrm{PMC}$, (b) interaction effect of temperature and air velocity on PMC, (c) interaction effect of drying time and air velocity on PMC, (d) interaction effect of drying time and relative humidity on $\mathrm{PMC}$, and (e) interaction effect of drying time and temperature on PMC of the dried chilli pepper. 


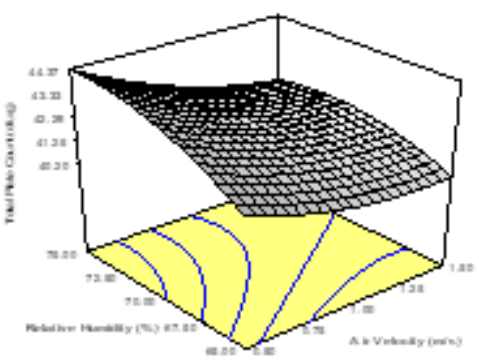

(a)

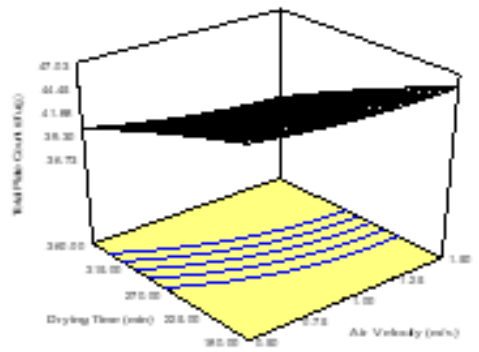

(c)

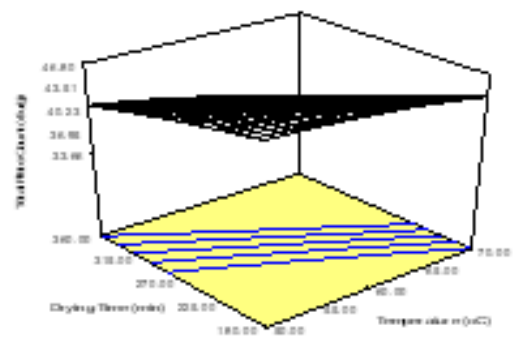

(e)

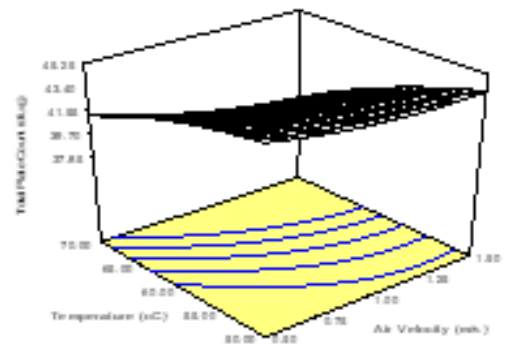

(b)

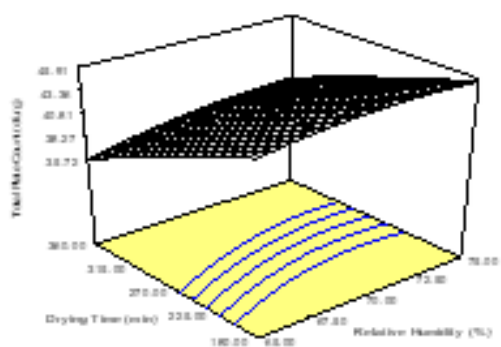

(d)

\section{Figure 4}

Three dimensional (3D) response surface plot indicating the: (a) interaction effect of relative humidity and air velocity on TPC, (b) interaction effect of temperature and air velocity on TPC, (c) interaction effect of drying time and air velocity on TPC, (d) interaction effect of drying time and relative humidity on TPC, and (e) interaction effect of drying time and temperature on TPC of the dried chilli pepper. 


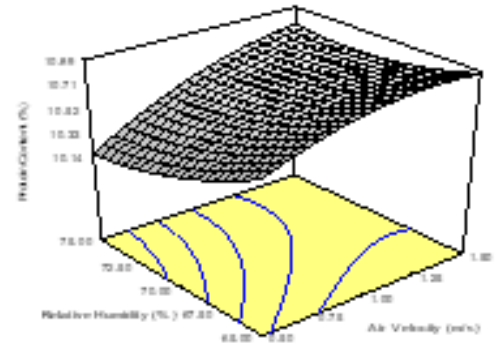

(a)

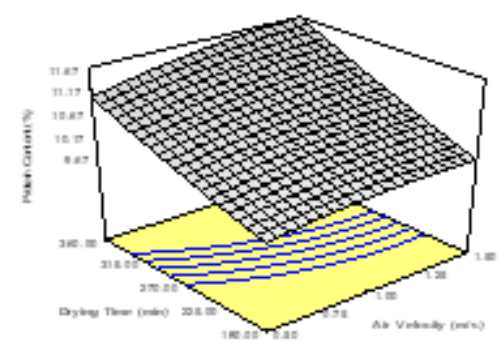

(c)

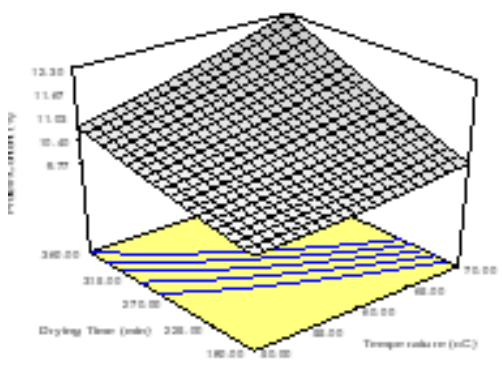

(e)

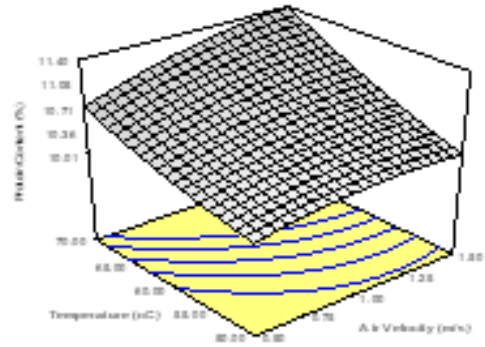

(b)

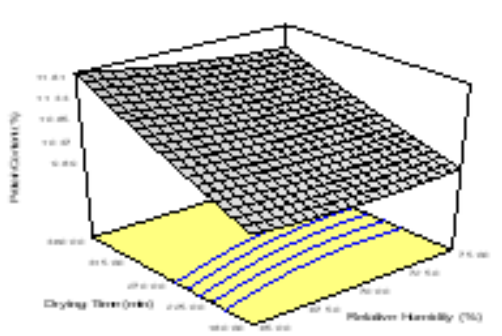

(d)

Figure 5

Three dimensional (3D) response surface plot indicating the: (a) interaction effect of relative humidity and air velocity on $\mathrm{PC}$, (b) interaction effect of temperature and air velocity on $\mathrm{PC}$, (c) interaction effect of drying time and air velocity on $\mathrm{PC}$, (d) interaction effect of drying time and relative humidity on $\mathrm{PC}$, and (e) interaction effect of drying time and temperature on PC of the dried chilli pepper. 


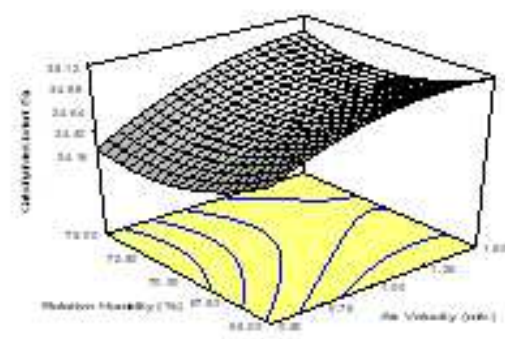

(a)

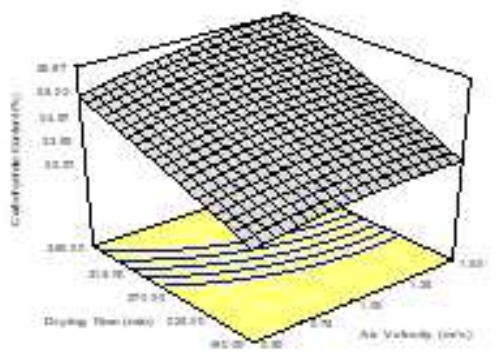

(c)

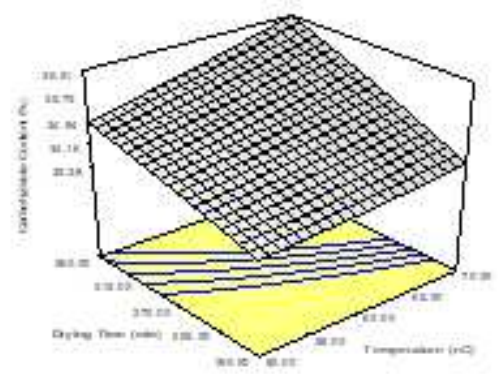

(e)

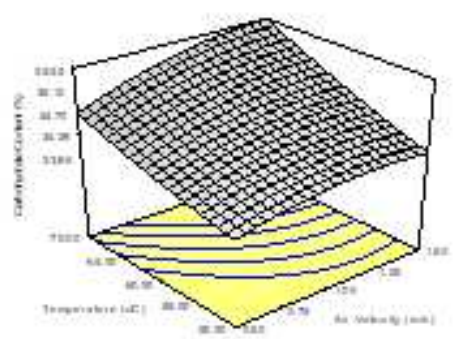

(b)

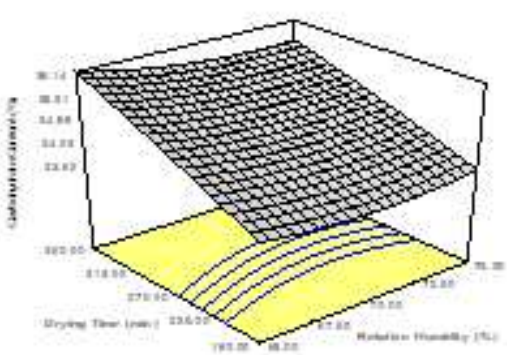

(d)

\section{Figure 6}

Three dimensional (3D) response surface plot indicating the: (a) interaction effect of relative humidity and air velocity on $\mathrm{CC}$, (b) interaction effect of temperature and air velocity on $\mathrm{CC}$, (c) interaction effect of drying time and air velocity on $\mathrm{CC}$, (d) interaction effect of drying time and relative humidity on $\mathrm{CC}$, and (e) interaction effect of drying time and temperature on CC of the dried chilli pepper. 


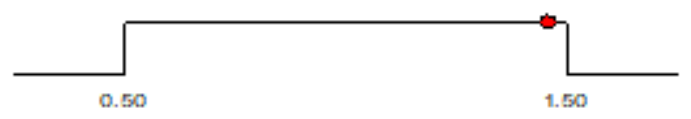

Air Vollocity $=1.46$

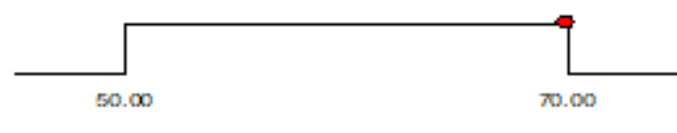

Temperature $=69.98$

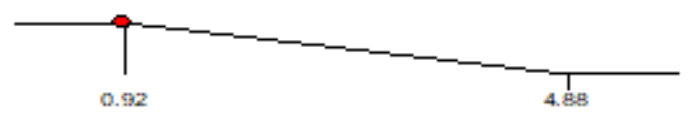

$\mathrm{PMC}=0.90$

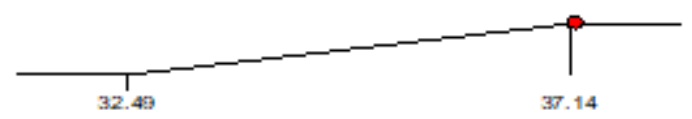

$\mathrm{CC}=37.22$

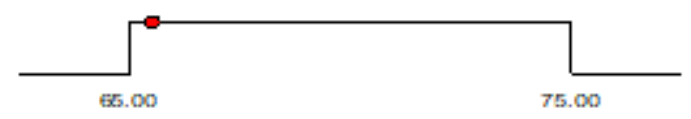

Robativs Humidity $=65.57$

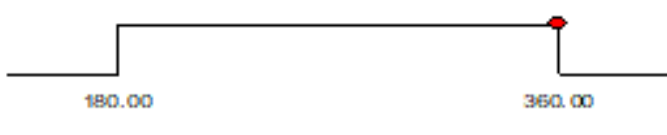

Drying Time $=359.96$

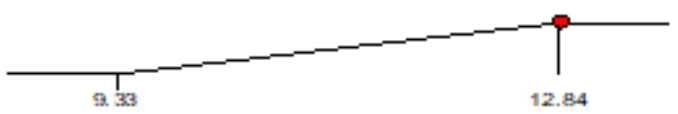

$\mathrm{PC}=12.87$

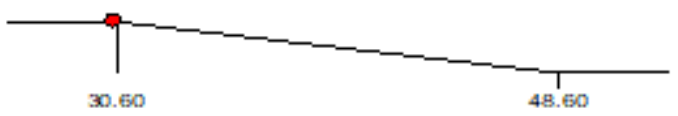

$\mathrm{TPC}=30.51$

Desirability $=1.000$

\section{Figure 7}

Ramps (desirability plot) showing predicted optimum values for the drying process conditions and predicted optimum values for the corresponding responses (quality attributes).

\section{Supplementary Files}

This is a list of supplementary files associated with this preprint. Click to download.

- GraphicalAbstractBIOBIOP.docx 